\title{
Evaluation of the Nutraceutical Potential of Rytidophyllum tomentosum (L.) Mart.: HPTLC Fingerprinting, Elemental Composition, Phenolic Content, and in vitro Antioxidant Activity
}

\author{
Yvonne A. Bailey-Shaw*, Colleen N. A. Salmon, Cheryl E. Green, Sheridan L. Hibbert, Ann Marie \\ Smith, and Lawrence A. D. Williams
}

Product Research and Development Division, Natural Products Unit, Scientific Research Council, Hope Gardens Complex, P.O. Box 350, Kingston 6. Jamaica W.I.

\begin{abstract}
Rytidophyllum tomentosum (L.) Mart. (search-me-heart) is an aromatic Jamaican endemic herb traditionally consumed as a general tonic and for its medicinal properties. This present study evaluates the nutraceutical potential of $R$. tomentosum as a functional herbal tea, through the assessment of elemental composition, phenolic contents and in vitro antioxidant potential of samples collected from five locations in Jamaica. High Performance Thin Layer Chromatography (HPTLC) is used to fingerprint the aqueous plant extract for identification and the nutraceutical value of the herb is compared with two commercial black teas. Results provide a detailed summary of the elemental composition of the plant infusion. Total polyphenols were determined to be in the range of $12.19 \pm 1.79-31.05 \pm 0.65 \mathrm{mg}$ gallic acid equivalent (GAE)/g dry powder, decreasing in the order of SMH/71/116 $>\mathrm{SMH} / 82 / 28>\mathrm{SMH} / 71 / 2>\mathrm{SMH} / 71 / 76>\mathrm{SMH} / 71 / 147$. Total flavonoids ranged from $6.81 \pm 0.07-21.41 \pm 0.61 \mathrm{mg}$ catechin equivalent $(\mathrm{CE}) / \mathrm{g}$ dry powder and decreased in the order of SMH/71/116 $>\mathrm{SMH} / 82 / 28>\mathrm{SMH} / 71 / 2>\mathrm{SMH} / 71 / 76>\mathrm{SMH} / 71 / 147$. Total tannins ranged from $10.60 \pm 0.15-$ $26.83 \pm 0.35 \mathrm{mg}$ tannic acid equivalent (TAE) $/ \mathrm{g}$ dry powder and decreased in the order of: $\mathrm{SMH} / 71 / 116>\mathrm{SMH} / 82 / 28>$ $\mathrm{SMH} / 71 / 2>\mathrm{SMH} / 71 / 76>\mathrm{SMH} / 71 / 147$. Search-me-heart from all locations possessed antioxidant activity irrespective of the method of analysis used. These findings along with the results of the comparative analysis to the two commercial black teas, suggest that search-me-heart could be an effective natural antioxidant and therefore could be positioned as a dietary herbal supplement in its herbal tea form.
\end{abstract}

Keywords: Rytidophyllum tomentosum, Antioxidant activity, Flavonoids, HPTLC, Nutraceutical potential, Phenolic contents, Polyphenols, Tannins.

\section{INTRODUCTION}

Herbal teas are aqueous preparations made from the barks, roots, seeds, flowers, leaves or fruits of trees and shrubs. They are however, not true "teas" since they are not obtained from the tea plant, Camellia sinensis (L.) Kuntze. Herbal teas are usually prepared as infusions or decoctions by submerging the plant material in hot or cold water or boiling respectively for a prescribed length of time [1-3].

However, regardless of the mode of preparation, there is no question, that in recent times herbal teas have gained tremendous popularity due to their health promoting properties. Their use as general tonics, dietary supplements, prophylactic agents, as well as their use for the treatment of various ailments, having been positioned as cold remedies, anti-stress, anti-viral or even digestive aids, to name a few [4-6], have highlighted the growing trend in the promotion of herbal teas as 'well-being', functional or nutraceutical

*Address correspondence to this author at Product Research and Development Division, Natural Products Unit, Scientific Research Council, Hope Gardens Complex, P.O. Box 350, Kingston 6. Jamaica W.I;

Tel: 876-927-1771; Fax: 876-977-2194;

E-mail: yvonneb@src-jamaica.org beverages. In fact, functional beverages have been cited as the fastest growing segment in the functional food category [7]. Consumers, in recent times have also been trending towards the use of natural ingredients in an effort to lead healthier lifestyles. Additionally, information on the effects of the use of certain ingredients has become increasingly available due to technological advancements: information technology / internet and research and development. As a result, the negative effects of caffeine and the high levels of tannin, an anti-nutritional factor in the widely consumed tea: C. sinensis have been publicized. On the other hand, the healthy caffeine-free alternative offered by low-calorie herbal teas has resulted in an increase in the market for herbal teas. This has been further strengthened by a "consuming-and-experience-culture", as well as globalization, resulting in consumers looking for new and exotic tastes [1], an opportunity offered by the myriad of herbal teas available on the global market.

Herbal teas and remedies are widely accepted and utilized within the Caribbean region [8] and form part of our rich heritage. Jamaica is no exception, with previous reports showing a traditional dependency on the use of medicinal plants to treat illness, as well as an extensive knowledge of herbal remedies recommended by traditional practitioners $[9$, 
10]. Herbal teas or "bush teas", as they are known in Jamaica, are highly regarded, and although consumed in urban areas, their uses are more deeply rooted in rural, remote communities [8], where the "folk medical system" (treating ailments with herbs) tends to be the primary form of healthcare available [11]. A number of local plants have traditionally been used as bush teas in Jamaica, with many being successfully marketed as herbal teas.

Rytidophyllum tomentosum (L.) Mart. (search-me-heart) is an aromatic shrub belonging to the family Gesneriaceae. It is a Jamaican endemic which grows wild on open banks in pastures in Jamaica. It may grow as high as $3 \mathrm{~m}$ and bears flowers and fruits all year. The leaves are alternate, longtapered at both ends and are light green and toothed. The flowers are hairy, bell-shaped and greenish yellow and are often marked with purplish red inside. They are constricted below the mouth, which is expanded with a prominent upper lip and protruding stamens $[12,13]$.

Search-me-heart has been identified as one of fifty herbs most commonly used in Jamaica $[8,9]$ and has been associated with many positive health benefits. Although mostly anecdotal, evidence suggests that search-me-heart may be used as a remedy for colds, to treat malnutrition, stomach pains, high blood pressure, asthma, worms and heart conditions $[9,10,13]$. It should be noted that only one documented scientific study on search-me-heart could be found by the authors. This study suggested that search-me-heart has anti-bacterial properties as well as low anti-helminthic activity [14]. Checks also revealed that there is a lively informal trade in some areas, where the herb is sold to be used as a component of "roots" drinks, which have markets locally and internationally. Search-me-heart has not yet transitioned to the mainstream herbal teas market, however all indications are that the potential for commercialization is high.

Encouraged by its suggested / reported health benefits, widespread use, the need for new and exotic tastes and further fueled by the general lack of scientific data, this study sought to undertake an investigation into the quality parameters of this herb with the overall objective of evaluating its nutraceutical potential as a functional herbal tea.

The specific objectives were to: collect and analyze search-me-heart samples from five locations across Jamaica in order to assess the potential for variability; to establish a standardized chromatographic fingerprint to be used for identification of the plant; to establish criteria for quality and strength by the determination of elemental composition (including heavy metals), antioxidant activity and phenolic constituents e.g. flavonoids, polyphenols and tannins, and to determine the general acceptance of the herb as a functional herbal tea through sensory analysis. For the purpose of this study, the terms infusion(s) and herbal tea(s) are used interchangeably.

\section{MATERIALS AND METHODS}

\section{Standards and Reagents}

Standards of quercetrin, isoquercetin, avicularin, kaempferol, ferulic acid, chlorogenic acid, caffeic acid and procatechuic acid were obtained from Chromadex Inc., Ir- vine, CA, USA. Quercetin dihydrate and myrecitin were obtained from MP Biomedicals LLC, Solon, OH, USA. Rutin monohydrate, tannic acid, catechin, gallic acid monohydrate, ascorbic acid, 2-aminoethyl dipheny borinate (Natural Products Reagent), Trolox, 2,2-Diphenyl-1-picryl-hydrazyl (DPPH), 2,2'-azinobis-3-ethylbenzothiazoline-6-sulfonic acid $\left(\mathrm{ABTS}^{+}\right)$, Folin Ciocateau's phenol reagent $-2 \mathrm{~N}$, formic acid, indigocarmine dye, sodium nitrite, aluminium chloride hexahydrate and potassium persulfate were obtained from Sigma Chemicals, St. Louis, MO, USA and Sigma Aldrich Co., Milwaukee, WI, USA. Polyethylene glycol 4500 and sodium carbonate (GPR) were obtained from Spectrum Chemical MFG Corp, CA, USA. and British Drug Houses (BDH) Laboratory Supplies, Poole, England, respectively. Analytical grade ethanol, ethyl acetate and methanol were obtained from Pharmco Products, Brookfield, CT, USA. Sodium hydroxide pellets, standard elements ( $\mathrm{Fe}, \mathrm{Cu}, \mathrm{Mn}$, $\mathrm{Zn}, \mathrm{Al}, \mathrm{Ca}, \mathrm{Cr}, \mathrm{K}, \mathrm{Mg}, \mathrm{Na}, \mathrm{Ni}, \mathrm{P}, \mathrm{Se}, \mathrm{Hg}, \mathrm{Cd}, \mathrm{Pb}$, and $\mathrm{As}$ ), Analytical grade glacial acetic acid, hydrochloric acid, nitric acid, potassium permanganate and HPLC grade glacial acetic acid and methanol were obtained from Fisher Scientific, Fair Lawn, NJ, USA. All other solvents, unless otherwise stated, were of analytical grade.

\section{Plant Material}

Search-me-heart leaves and stems were collected from their natural habitats in five locations across the island. Samples were coded SMH/71/2 - Location 1, SMH/71/76 - Location 2, SMH/71/116- Location 3, SMH/71/147- Location 4 and SMH/82/28 - Location 5. Samples were identified and authenticated taxonomically by comparison with voucher specimens at the Herbarium of the University of the West Indies, Mona, Kingston, Jamaica. Samples were air dried for 5 -7 days after which they were milled to a coarse powder prior to extraction. Excess material was stored in sealed plastic bags. Commercial teas, Black Tea A teabags and Black Tea B loose leaves were used for comparative analyses and were purchased from a local supermarket.

\section{Sample Preparation}

Infusions were prepared according to the method of Rapavi et al., [15] to which minor modifications were made. Approximately $1 \mathrm{~g}$ of powdered search-me-heart or commercial tea was infused in $100 \mathrm{~mL}$ of boiling distilled water and covered. This was allowed to stand for 5 mins at room temperature, after which it was filtered and the volume made up to $100 \mathrm{~mL}$. Extractions were conducted in triplicate. These were used for further analyses. Samples of the infusions were also lyophilized (Labconco Freeze Zone 4.5 Liter Freeze Dry System - Model 7750001) for DPPH antioxidant study.

\section{High Performance Thin Layer Chromatography (HPTLC) Fingerprinting of Polyphenols}

The chromatographic fingerprints of the aqueous extracts of search-me-heart were developed using a HPTLC method developed in our laboratory.

Aqueous extracts of powdered search-me-heart were prepared by adding $10 \mathrm{~mL}$ of water to approximately $1 \mathrm{~g}$ of powdered search-me-heart weighed in $50 \mathrm{~mL}$ round bottom flasks. The contents of the flasks were then boiled under 
reflux for 10 mins. The flasks were cooled, filtered and concentrated under vacuum on a rotary evaporator. The residues obtained were then redissolved in $2 \mathrm{~mL}$ of methanol and filtered through a filter of $0.45 \mu \mathrm{m}$ pore size. Individual polyphenol standard solutions (flavonoids - rutin, quercetin, quercetrin, isoquercetin, avicularin, myricetin, and kaempferol; phenolic acids - ferulic, gallic, tannic, chlorogenic, caffeic, and procatechuic acids) were prepared in methanol at concentrations of $0.3 \mathrm{mg} / \mathrm{mL}$.

Analyses were carried out using a Camag HPTLC system (Wilmington, NC., USA) made up of a Linomat 5 semiautomatic sample applicator, twin-trough plate development chambers $(10 \times 10 \mathrm{~cm}$ or $20 \times 10 \mathrm{~cm})$, Reprostar 3 / Digistore 2 documentation system and Wincats integration software.

Individual standard solutions ( $2 \mu \mathrm{L})$ and samples $(5 \mu \mathrm{L})$ were applied by means of the Linomat 5 sample applicator to $10 \times 10 \mathrm{~cm}$ or $20 \times 10 \mathrm{~cm}$ HPTLC silica gel $60 \mathrm{~F}_{254}$ glass plates (Merck, Darmstadt, Germany), prewashed by development with methanol and activated at $120{ }^{\circ} \mathrm{C}$ for 20 mins. Bands were $6 \mathrm{~mm}, 10 \mathrm{~mm}$ from the lower edge of the plate and $20 \mathrm{~mm}$ from the left edge of the plate. The distance between tracks/bands varied, depending on number of tracks and plate dimensions. Chromatograms were developed up to $90 \mathrm{~mm}$ in twin trough chambers $(10 \times 10 \mathrm{~cm}$ or $20 \times 10 \mathrm{~cm})$ saturated for 20 mins using a solvent system consisting of ethyl acetate - acetic acid - formic acid - water (104:11:7:26 , v/v). The developed plates were air dried with a hair dryer (cold air) for 3 mins, then documented with a Reprostar 3 / Digistore 2 Documentation System using illumination at 254 $\mathrm{nm}, 366 \mathrm{~nm}$ and under white light. They were then heated at $100{ }^{\circ} \mathrm{C}$ for $5 \mathrm{mins}$ and derivatized by spraying evenly with a solution of $0.5 \%$ 2-aminoethyl dipheny borinate in ethylacetate ( Natural Products Reagent) followed by $5 \%$ polyethylene glycol in dichloromethane under the fume hood. Drying was carried out immediately on a plate heater set at $100{ }^{\circ} \mathrm{C}$ for 5 mins. The derivatized plates were cooled to room temperature then documented at $254 \mathrm{~nm}, 366 \mathrm{~nm}$ and under white light. $R_{f}$ values were determined using the Wincats software.

\section{Analysis of Elements}

Contents of 17 elements ( $\mathrm{Fe}, \mathrm{Cu}, \mathrm{Mn}, \mathrm{Zn}, \mathrm{Al}, \mathrm{Ca}, \mathrm{Cr}, \mathrm{K}$, $\mathrm{Mg}, \mathrm{Na}, \mathrm{Ni}, \mathrm{P}, \mathrm{Se}, \mathrm{Hg}, \mathrm{Cd}, \mathrm{Pb}$, and $\mathrm{As}$ ) in the infusions prepared from the five locations were determined. Elemental content was determined according to the methods of Eaton et al., [16] as outlined for the specific elements. All determinations were made by flame atomic absorption spectrophotometry, with the exception of As and Se, which were determined by colourimetry. For elements determined by flame atomic absorption spectrophotometry, the infusions were prepared as in Sample Preparation and were aspirated into the atomic absorption spectrophotometer without any further treatment. Quantitative determinations of the elements in the samples were made using calibration curves prepared from standard calibration solutions of each element prepared in water with concentration ranges between 1-3 mg/L. Exceptions were magnesium $(\mathrm{Mg})$ and manganese $(\mathrm{Mn})$, which were prepared at concentrations ranging between $0.1-0.3$ $\mathrm{mg} / \mathrm{L}$. Concentration of elements in the sample solutions were calculated as $\mathrm{mg} / \mathrm{L}$ of each.
Determination of the Phenolic Constituents of SearchMe-Heart Infusions

\section{Determination of Total Polyphenols}

Total polyphenols in search-me-heart infusions were measured by the Folin-Ciocalteu (F-C) colourimetric method as outlined by Marinova et al., [17] and to which minor modifications were made. A $1 \mathrm{mg} / \mathrm{mL}$ gallic acid stock solution was prepared by accurately weighing out $0.100 \pm 0.001$ $\mathrm{g}$ of gallic acid monohydrate and making up to $100 \mathrm{~mL}$ in a volumetric flask. This solution was prepared fresh daily. 1 $\mathrm{mL}$ of the stock solution was transferred to a $10 \mathrm{~mL}$ volumetric flask and diluted to the mark $(0.1 \mathrm{mg} / \mathrm{mL})$. Volumes of 0.0 (control), $0.2,0.4,0.6,0.8$, and $1.0 \mathrm{~mL}$ of $0.1 \mathrm{mg} / \mathrm{mL}$ of gallic acid standard solutions were transferred to $25 \mathrm{~mL}$ volumetric flasks containing $9 \mathrm{~mL}$ of distilled water in duplicate. $1 \mathrm{~mL}$ of $10 \%$ diluted $\mathrm{F}-\mathrm{C}$ reagent was added to each flask and mixed. After $5 \mathrm{mins}, 10 \mathrm{~mL}$ of $7 \%(\mathrm{w} / \mathrm{v})$ sodium carbonate solution was added and mixed. The solutions were then diluted to the $25 \mathrm{~mL}$ mark with distilled water and allowed to incubate at room temperature for $30 \mathrm{mins}$. Searchme-heart and commercial teas infusions were treated similarly. Absorbances were read immediately after at $750 \mathrm{~nm}$. The total polyphenol content was expressed as gallic acid equivalents ( $\mathrm{mg} / \mathrm{g}$ dry powder and $\mathrm{mg} /$ serving herbal infusion or tea). All samples were analyzed in duplicates.

\section{Determination of Total Flavonoids}

Total flavonoids in infusions of search-me-heart and commercial teas were measured using the aluminium chloride colourimetric method according to Marinova et al., [17]. Total flavonoid content was expressed as catechin equivalents $(\mathrm{mg} / \mathrm{g}$ dry powder and $\mathrm{mg} /$ serving herbal infusion or tea). Samples were analysed in duplicates.

\section{Determination of Total Tannins}

Total tannins in the infusions were estimated according to the indigo carmine method as outlined by Rajpal [18], with minor modifications. $1 \mathrm{~mL}$ of the infusion was measured into a $250 \mathrm{~mL}$ conical flask to which water $(75 \mathrm{~mL})$ and indigosulphonic acid solutions $(2.5 \mathrm{~mL})$ were then added. This was then titrated with constant stirring against a N/1000 potassium permanganate solution to a golden yellow colour. A blank test was run by titrating $2.5 \mathrm{~mL}$ of indigosulphonic acid in $75 \mathrm{~mL}$ of water. Infusions of commercial teas were treated similarly. The concentration of tannin was estimated using the following relationship: $1 \mathrm{~mL}$ of $\mathrm{N} / 10$ potassium permanganate is equivalent to $0.004157 \mathrm{~g}$ of tannin compounds calculated as tannic acid. Total tannins were expressed as tannic acid equivalent (mg/g dry powder or $\mathrm{mg} /$ serving herbal infusion or tea where 1 serving / cup $=200$ $\mathrm{mL})$. Samples were analysed in duplicates.

\section{Determination of In Vitro Antioxidant Activity}

In vitro antioxidant activities of search-me-heart aqueous extracts as well as the commercial teas infusions were evaluated using three different assays: DPPH [19], F-C reducing capacity [17] and Trolox Equivalent Antioxidant Capacity / TEAC [20].

\section{DPPH Antioxidant Assay}

A stock solution of $5.0 \mathrm{mg} / \mathrm{mL}$ was prepared using the lyophilized infusion of search-me-heart from each location. 
$20 \mu \mathrm{L}$ of this solution was then added to $2.0 \mathrm{~mL}$ of methanol to produce a final testing concentration of $50 \mu \mathrm{g} / \mathrm{mL} .400 \mu \mathrm{L}$ of $0.02 \%(\mathrm{w} / \mathrm{v})$ stock solution of 2, 2-diphenyl-1picrylhdrazl (DPPH) in methanol was then added to the solution and incubate the mixture for 20 mins. Lyophilized infusions of commercial teas were treated similarly. Absorbance was determined at $517 \mathrm{~nm}$ against a methanol blank using a spectrophotometer. All samples were measured in duplicates. The percentage anti-oxidant activity ( $\%$ AA) was determined by the following equation:

$\% \mathrm{AA}=\underline{\text { Absorbance of control }- \text { Absorbance of sample } \times 100}$ Absorbance of control

\section{Folin-Ciocalteu (F-C) Reducing Capacity Assay}

The procedure used was as described for the determination of total polyphenols however, the gallic acid was substituted with ascorbic acid. Total antioxidant activity was measured in search-me-heart and commercial tea infusions and expressed as mg equivalents of ascorbic acid per g dry powder and $\mathrm{mg} /$ serving herbal infusion or tea. All samples were analysed in duplicates.

\section{Trolox Equivalent Antioxidant Capacity (TEAC) Assay}

A stable stock solution of $\mathrm{ABTS}^{+}$was produced by reacting a $7 \mathrm{mM}$ aqueous solution of ABTS with aqueous 2.45 $\mathrm{mM}$ potassium persulfate (final concentrations). The mixture was allowed to stand in the dark for $12-16 \mathrm{hr}$ before use. The aqueous working solution was prepared by dissolving the ABTS radicalized solution above in ethanol $(1: 90, \mathrm{v} / \mathrm{v})$ to an absorbance of $0.700 \pm 0.002$ at $734 \mathrm{~nm}$ at room temperature.

A standard Trolox $1 \mathrm{mM}$ stock solution was prepared in ethanol and diluted to different concentrations between 0 $\mathrm{mM}$ (blank) to $1.0 \mathrm{mM}$ in water and conserved in the dark. The dilutions were $1 / 5,2 / 5,3 / 5,4 / 5,5 / 5$ and these were prepared in duplicate. $20 \mu \mathrm{L}$ of each standard Trolox solution or the search-me-heart/commercial tea infusions was added to 2 $\mathrm{mL}$ of ABTS working solution and vortexed for approximately $30 \mathrm{sec}$ and incubated at room temperature for 40 mins. Absorbance readings were taken at $734 \mathrm{~nm}$ immediately after. Results were expressed as TEAC (mg/g dry powder and $\mathrm{mg} /$ serving herbal infusion or tea).

Plate 1

Prior to Derivatization @ 366 nm

After Derivatization @ 366 nm

Plate 2

\section{Sensory Analysis}

A representative sample of search-me-heart coded $\mathrm{SMH} / 71 / 116$ was used to prepare herbal tea samples for sensory analysis. The plant material was pretreated by washing with potable water, steam drying and milling to a coarse powder. The herbal infusions were then prepared in boiling water according to the procedure described under Sample Preparation at two strengths. A complete randomized block design was used, in which the samples were coded with three digit random numbers and served in identical presentation style. The ratio of material weight to cup volumes used were $1 \mathrm{~g}: 100 \mathrm{~mL}$ (Coded 502) and $2 \mathrm{~g}: 100 \mathrm{~mL}$ (Coded 728). Sensory analysis was conducted using 27 trained panelists who were placed in isolated booths and provided with presweetened samples. Four sensory attributes were evaluated: colour, aroma, flavour and overall acceptance. Panelists were provided with water to clean their palates after every tasting. Affective testing was conducted using a nine-point hedonic scale $[21,22]$.

\section{Graphs and Statistical Analyses}

Summary statistics and graphs were obtained using Microsoft Office Excel 2007. Means were compared using analysis of variance (ANOVA) at $\mathrm{p} \leq 0.05$.

\section{RESULTS AND DISCUSSION}

\section{HPTLC Fingerprint of Search-Me-Heart}

Due to the relationship between polyphenolic compounds and antioxidant activity as well as bioactivity; and since the aim of the study was to evaluate the nutraceutical potential of the herbal tea, it was imperative to focus on developing a chromatographic fingerprint of the water soluble polyphenols.

Representative chromatograms of the HPTLC profile of the aqueous extracts are shown in Figs. (1-3), with Tables 13 giving details with respect to spot colours and $R_{f}$ for the respective chromatograms. Fig. (1) is a comparison of the profiles of the aqueous extracts of search-me-heart from the five locations investigated. Table 1 gives details of the spot colours and corresponding $R_{\mathrm{f}}$ values. Examination of Plate 2 (Fig. 1) clearly suggests that the majority of compounds pre-

Plate 3

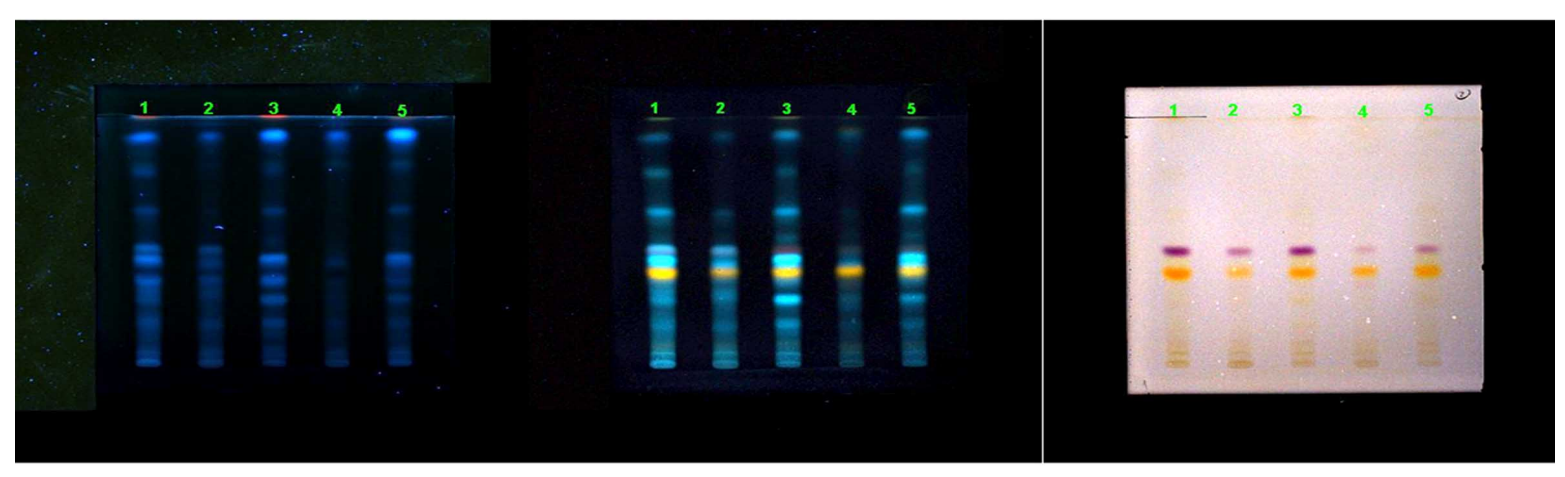

Fig. (1). HPTLC Profiles of Aqueous Extracts of Search-Me-Heart from Five Locations.

1- SMH/71/2, 2 - SMH/71/76, 3 - SMH/71/116, 4 - SMH/71/147, 5 - SMH/82/28.SMH/71/2 - Location 1, SMH/71/76 - Location 2, $\mathrm{SMH} / 71 / 116$ - Location 3, SMH/71/147 - Location 4, SMH/82/28 - Location 5. 
Table 1. Spot Colours and Corresponding $R_{f}$ Values of Aqueous Extracts of Search-Me-Heart (Plate 2)

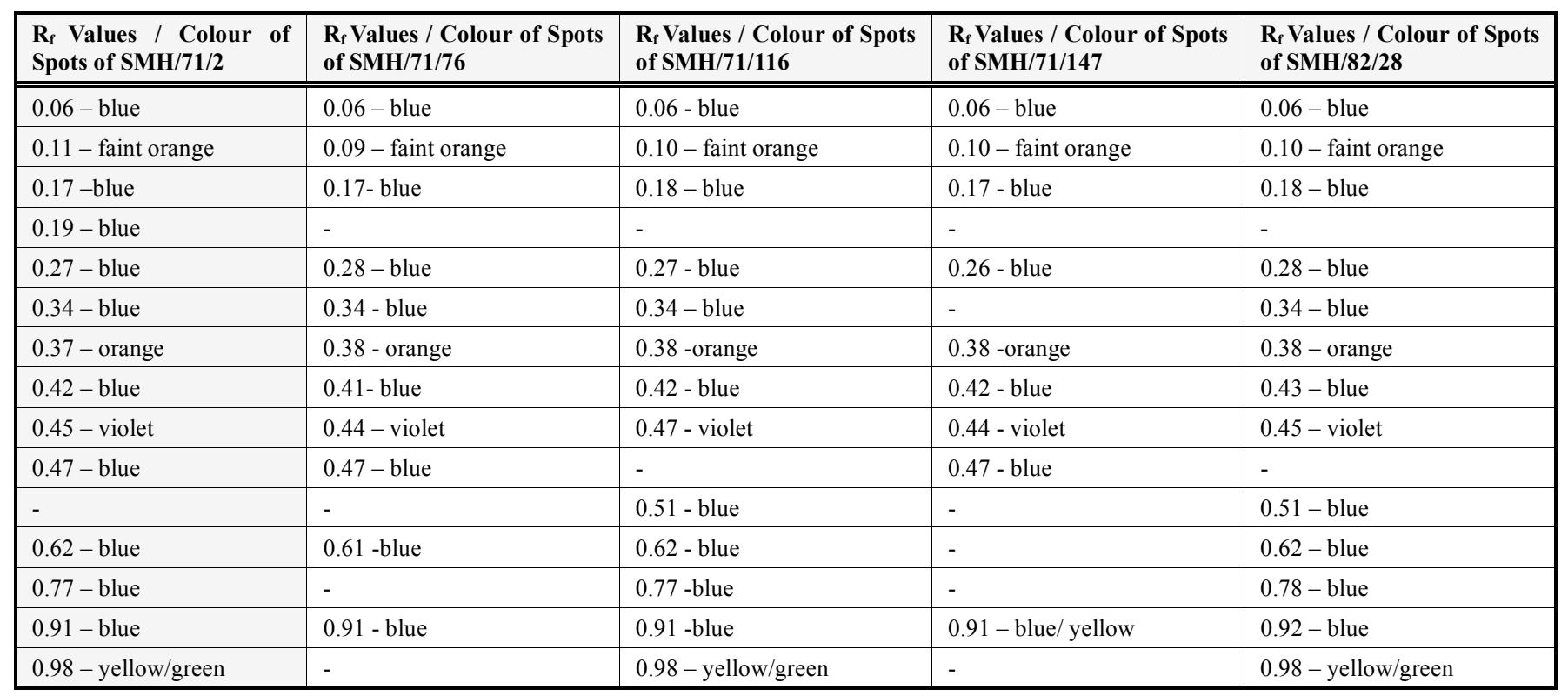

sent in search-me-heart aqueous extracts are phenolic acids; indicated by the blue bands, with a minute quantity of flavonoids; indicated by the orange bands. There appeared to be some similarities between extracts in Tracks 1 and 2 and Tracks 3 and 5 respectively.

Track 1 however, had more intensely coloured bands when compared with Track 2, suggesting that there may be a higher concentration of the common compounds present in this extract. Additionally two more bands $\left(\mathrm{R}_{\mathrm{f}}-0.19\right.$ (blue), 0.98 (yellow-green)) than were identified in Track 2 were observed in Track 1, suggesting not only higher concentrations of polyphenolic compounds but a slightly more complex sample matrix. Identical coloured bands with almost similar $\mathrm{R}_{\mathrm{f}}$ values were observed in Tracks 3 and 5. Track 4 was however different, in that the extract appeared to contain far less compounds (nine versus eleven - fourteen) than identified in the others. Bands corresponding to similar bands in the other extracts also appeared to be less intensely coloured in Track 4, suggesting that these compounds may also be occurring in lower concentrations. Plate 3 (Fig. 1) clearly shows the occurrence of an unidentified compound, violet in colour which appeared in all samples, albeit at higher concentrations in those indicated by the more intense colourations (Tracks 1-3).

In attempting to identify marker compounds (for standardization purposes) in the search-me-heart aqueous extract, a comparison of extracts from the five locations was made against standards of phenolic acids and flavonoids. Fig. (2), Table 2 represents the results of this comparison. Caffeic acid was found to be common to all the extracts (Fig. 2, Plate 2 ). This was confirmed by comparing the $R_{f}$ value of the band for the caffeic acid standard with those of the corresponding band in the samples (Table 2). The fact that only a single matching band was found should not be taken as an indication that no other standard used in the comparison was present in the sample. However, it should be noted that these compounds may have been present in concentrations which were too low to have been visualized by HPTLC. Fig. (3),
Table 3 represents a comparison between the water extracts and the caffeic acid standard and clearly shows the occurrence of caffeic acid at what appears to be various concentrations based on intensity of colourations in all sample extracts. These results indicate overall that, the HPTLC method employed is a reliable means by which to identify and assess the fingerprints of the major active constituents in the aqueous samples of search-me-heart. This in turn can be used to provide the basis for their use as a functional herbal tea.

\section{Elemental Content of Search-Me-Heart}

The human body requires both metallic and non-metallic elements for growth and good health. At least 50 elements vital to the well-being of humans have been identified. However, their intake has to be within certain permissible limits $[23,24]$. In order to understand the nutritive importance as well as determine whether the amounts consumed as beverages in normal doses may be toxic, the elemental composition of the infusions obtained for samples from the various locations was determined. Essential elements determined were $\mathrm{Fe}, \mathrm{Cu}, \mathrm{Mn}, \mathrm{Zn}, \mathrm{Ca}, \mathrm{C}, \mathrm{K}, \mathrm{Mg}, \mathrm{Ni}$, and $\mathrm{Se}$, with nonessential elements being $\mathrm{Al}, \mathrm{Hg}, \mathrm{Cd}, \mathrm{Pb}$, and $\mathrm{As}$. Results of the analyses are presented in Table 4.

The infusions were generally found to contain low concentrations of the elements with the exception of $\mathrm{Ca}, \mathrm{K}, \mathrm{Mg}$, and $\mathrm{Na}$ which were present in relatively high concentrations. According to Karimi et al., [25], the metals chelate tannic acid and tannins released during preparation of the infusion, hence the precipitation of the chelates leads to the noticed decrease in the concentrations. Additionally, the author indicated that other factors such as the physiological properties of the structures of the plant, $\mathrm{pH}$ of the water used in the preparation of the infusion, extraction time, temperature and solubility of the elements in hot water could also affect the elemental concentrations in the infusions. Calcium (Ca) and potassium $(\mathrm{K})$ were the most abundant elements found. This is a slight variation from a previous study in which $\mathrm{Ca}$ and $\mathrm{Mg}$ were reported as the most abundant elements in many 

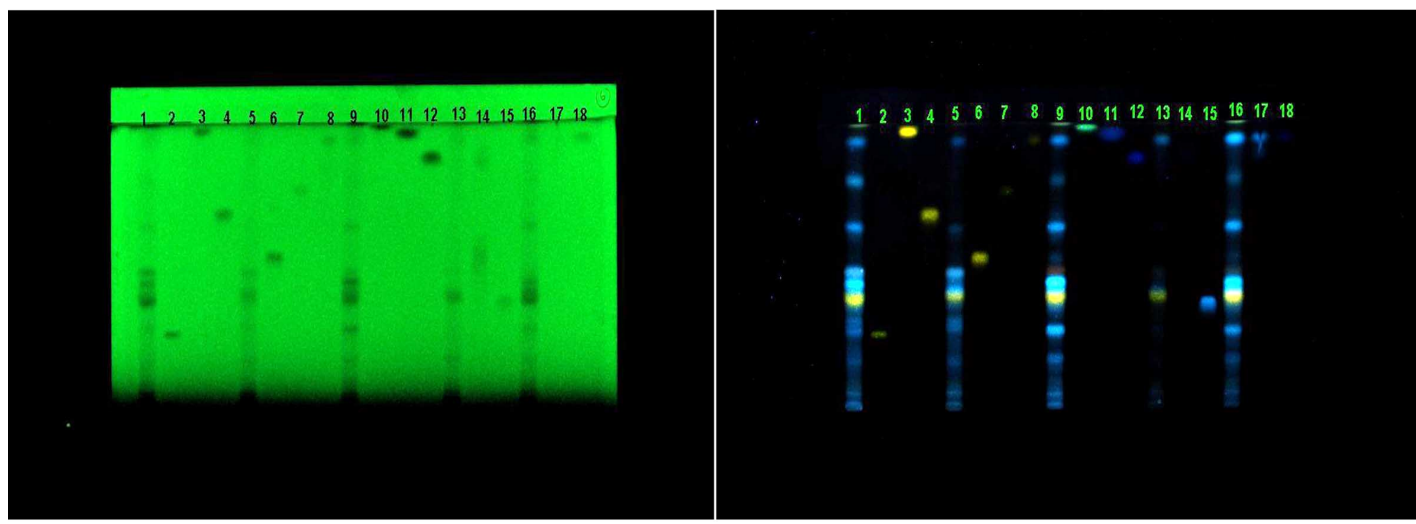

Fig. (2). HPTLC Profiles of Aqueous Extracts of Search-Me-Heart from Five Locations Against Phenolic Acids and Flavonoid Standards. 1 - SMH/71/2, 2 - Rutin , 3- Quercetin , 4 - Quercetrin , 5- SMH/71/76, 6 - Isoquercetin, 7- Avicularin, 8 -Myricetin, 9 - SMH/71/116, 10 Kaempferol, 11- Ferulic Acid , 12 - Gallic Acid ,13 - SMH/71/147, 14 -Tannic Acid, 15 - Chlorogenic Acid ,16 - SMH/82/28, 17 - Caffeic Acid, 18 - Procatechuic Acid.

SMH/71/2 - Location 1, SMH/71/76 - Location 2, SMH/71/116 - Location 3, SMH/71/147 - Location 4, SMH/82/28 - Location 5.

Table 2. Spots and Corresponding $\mathbf{R}_{\mathrm{f}}$ Values of Aqueous Extracts of Search-Me-Heart Against Phenolic Acids and Flavonoid Standards - Plate 2

\begin{tabular}{|c|c|c|c|c|c|}
\hline $\begin{array}{l}\mathbf{R}_{\mathrm{f}} \text { Values } \\
\text { Colour of Spots of Stan- } \\
\text { dards }\end{array}$ & 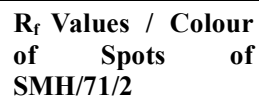 & $\begin{array}{l}R_{\mathrm{f}} \text { Values / Colour of } \\
\text { Spots of } \mathrm{SMH} / 71 / 76\end{array}$ & $\begin{array}{l}R_{f} \text { Values / Colour of } \\
\text { Spots of SMH/71/116 }\end{array}$ & $\begin{array}{l}\mathbf{R}_{\mathrm{f}} \text { Values / Colour of } \\
\text { Spots of SMH/71/147 }\end{array}$ & $\begin{array}{l}\mathbf{R}_{\mathrm{f}} \text { Values / Colour of } \\
\text { Spots of } \mathrm{SMH} / 82 / 28\end{array}$ \\
\hline 0.26 - orange (Rutin) & $0.05-$ blue & 0.05 - blue & $0.05-$ blue & $0.05-$ blue & 0.06 - blue \\
\hline $\begin{array}{l}0.52 \text { - orange (Isoquer- } \\
\text { cetin ) }\end{array}$ & $0.27-$ blue & - & $0.27-$ blue & - & $0.28-$ blue \\
\hline 0.67 - orange (Quercetrin) & $0.31-$ blue & & - & - & - \\
\hline $0.76-$ orange (Avicularin) & 0.35 - blue & 0.35 - blue & 0.35 - blue & - & 0.36 - blue \\
\hline 0.88 - blue (Gallic Acid) & 0.38 - orange & 0.39 - orange & 0.39 - orange & 0.39 - orange & 0.39 - orange \\
\hline 0.93 - blue (Caffeic Acid) & $0.43-$ blue & 0.42 - blue & $0.44-$ blue & $0.42-$ blue & $0.44-$ blue \\
\hline 0.94 - orange (Myricetin) & $0.47-$ blue & $0.47-$ blue & - & - & - \\
\hline 0.96 - orange (Quercetin) & 0.63 - blue & 0.62 - blue & 0.63 - blue & - & 0.63 - blue - \\
\hline \multirow[t]{3}{*}{0.97 - green (Kaempferol) } & $0.79-$ blue & - & 0.80 - blue & - & $0.80-$ blue \\
\hline & 0.93 - blue & 0.93 - blue & 0.93 - blue & 0.93 - blue & 0.93 - blue \\
\hline & $0.98-$ green & - & 0.98 - green & - & $0.98-$ green \\
\hline
\end{tabular}

Data in bold represent possible matches.

medicinal plants [24]. Optimal intakes of elements such as $\mathrm{Na}, \mathrm{K}, \mathrm{Mg}, \mathrm{Ca}, \mathrm{Mn}, \mathrm{Cu}$, and $\mathrm{Zn}$ have been reported to reduce individual risk factors, including those related to cardiovascular disease in both human and animal studies. Calcium is known to enhance the qualities of bones and teeth, neuromuscular systemic as well as cardiac functions [23]. The high concentrations of $\mathrm{Ca}$ and $\mathrm{K}$ in the plant material are therefore significant and could have implications in the treatment of cardiovascular conditions. It should be noted that search-me-heart herbal infusion is traditionally consumed for heart problems; however further studies will be needed in order to validate this claim. Mn was found to be present in the infusions, an important fact, since this element in addition to $\mathrm{Fe}, \mathrm{Cu}$, and $\mathrm{Zn}$ are deemed to be critical components in the antioxidant defence system of the human body [15]. Microessential elements: $\mathrm{Cr}, \mathrm{Ni}$ and Se were present at relatively low levels.

The heavy metals: $\mathrm{As}, \mathrm{Cd}, \mathrm{Hg}$ and $\mathrm{Pb}$ are best known for their toxicological properties $[23,24]$. Whereas $\mathrm{Cd}, \mathrm{Hg}$ and $\mathrm{Pb}$ were found in all samples, As was detected in the sample from only one location $(\mathrm{SMH} / 71 / 147)$ at a concentration $(<$ $10 \mathrm{mg} / \mathrm{L}$ ) higher than the WHO [26] permissible limit of 1 


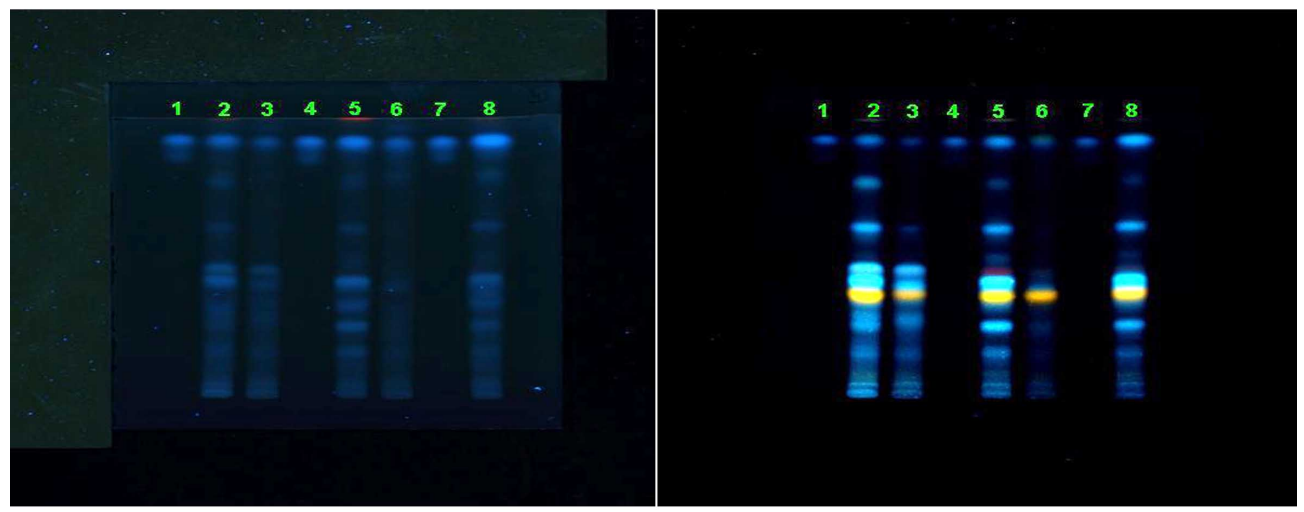

Fig. (3). HPTLC Profiles of Aqueous Extracts of Search-Me-Heart and Marker Compound (Caffeic Acid).

1, 4, 7 - Caffeic Acid (Marker), 2 - SMH/71/2, 3 - SMH/71/76, 5 - SMH/71/116, 6 - SMH/71/147, 8 - SMH/82/28.

$\mathrm{SMH} / 71 / 2$ - Location 1, SMH/71/76 - Location 2, SMH/71/116 - Location 3, SMH/71/147 - Location 4, SMH/82/28 - Location 5.

Table 3. Spots and Corresponding $R_{\mathbf{f}}$ Values of Aqueous Extracts of Search-Me-Heart and Marker Compound (Caffeic Acid) Plate 2

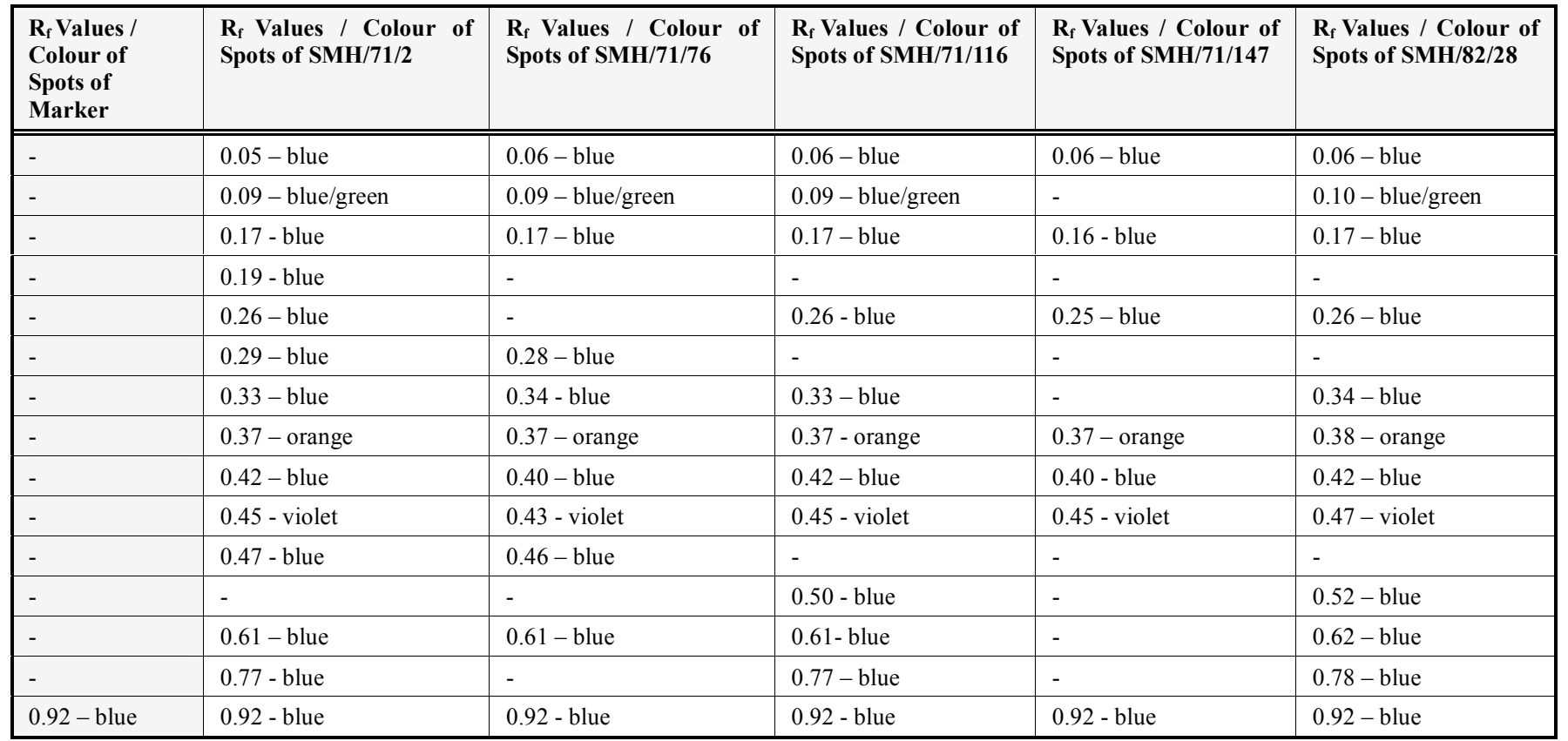

$\mathrm{mg} / \mathrm{kg}$. The levels of $\mathrm{Pb}$ and $\mathrm{Hg}$ detected in all the samples were below the permissible limit of $10 \mathrm{mg} / \mathrm{kg}$ WHO [27] and $1.0 \mathrm{mg} / \mathrm{kg}$ [28] respectively. Cd levels were also below the WHO [27] permissible limit of $0.3 \mathrm{mg} / \mathrm{kg}$ in the majority of samples, the exception being SMH/71/147 (7.5 mg/L)

\section{Correlation of Elemental Content and Search-Me-Heart Consumption}

There are currently no standard limits for trace elements in non-alcoholic beverages; hence their daily uptake from the consumption of search-me-heart infusions was determined in order to evaluate their potential hazard to health. Calculated results shown in Table 4 are based on the assumption that a single person consumes an average of three cups of infusion per day, with each cup brewed from $2 \mathrm{~g}$ of dried powder infused in $200 \mathrm{~mL}$ of boiling water, i.e. $6 \mathrm{~g}$ of search-me- heart powder per day. No recommended limits could be ascertained for Al and $\mathrm{P}$.

Calculated intakes of $\mathrm{Cu}, \mathrm{Zn}, \mathrm{Cr}, \mathrm{Na}$ and $\mathrm{Ni}$ were found to be below the recommended daily dietary intake in the samples from all locations, indicating that these essential elements may add to the micronutrient supply from other sources, but are not present in concentrations high enough to cause any adverse effects. Fe, Mn, $\mathrm{Ca}, \mathrm{K}, \mathrm{Mg}$, and Se were also found to be below the recommended daily dietary intake in all but one sample: $\mathrm{SMH} / 71 / 147$, which appeared to contain high levels of trace elements in general, resulting in the values for the upper ranges reported in Table 4. It should be noted that in the case of Fe, the toxic dose in adults is about $15-20 \mathrm{~g}$ [29], which would still make it relatively safe to consume the sample in question $(20.76 \mathrm{mg} /$ day $)$. Similarly, for $\mathrm{Ca}$, no adverse effects have been observed in healthy 
Table 4. Elemental Concentrations in Search-Me-Heart Infusions and Summary of Its Recommended and Calculated Daily Intake as an Infusion

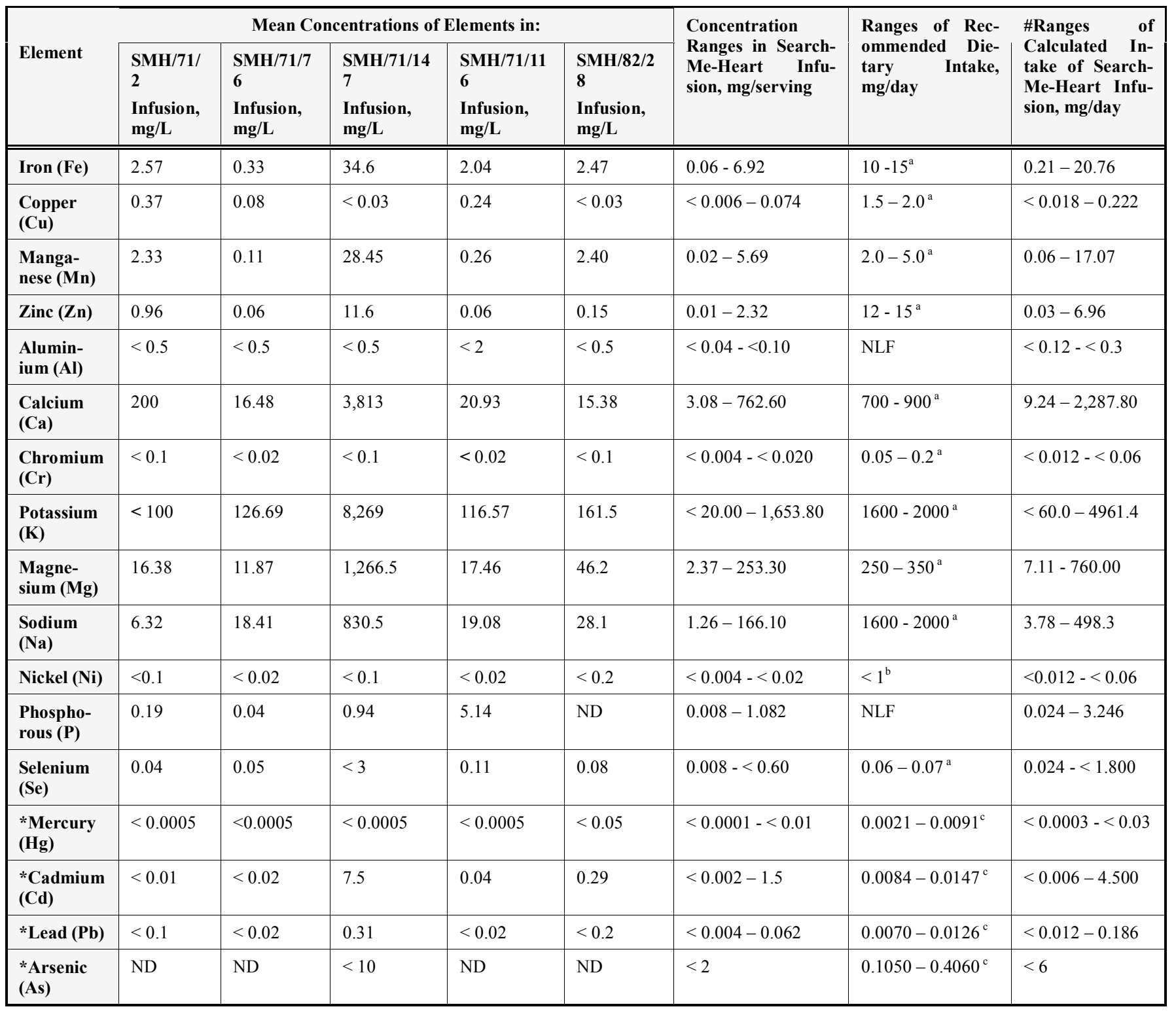

*Heavy Metals, $\mathrm{mg}$ /serving - Values represent content of a $200 \mathrm{~mL}$ cup of herbal tea ( $2 \mathrm{~g}$ search-me-heart powder in $200 \mathrm{~mL}$ boiling water); \#Assumption is that average consumption of search-me-heart herbal tea is three cups/day; NLF - No Limits Found; ND - Not Detected; ${ }^{\text {a }}$ - Source: Ref. \# 29; ${ }^{\text {b }}$ - Source: Ref. \# 51 ; $^{\text {c }}$ - Source: Ref. \# 24.

adults consuming up to $2,500 \mathrm{mg} /$ day, a limit which would place Ca intake from SMH/71/147 (2287.80 mg/day) within the safety zone. Excessive intake of more than $17.6 \mathrm{~g}$ of $\mathrm{K}$ per day may result in acute intoxication, if no increase losses from the body occur. Calculated intake of $\mathrm{K}$ from $\mathrm{SMH} / 71 / 147$ was $4961.4 \mathrm{mg} / \mathrm{day}$, a value far less than the level at which intoxication would occur. On the other hand, calculated intake of Se was found to be $1.8 \mathrm{mg}$ or 1,800 $\mu \mathrm{g} /$ day, a level which could result in severe toxicity based on the highly toxic nature of this element. Se is highly toxic at $750 \mu \mathrm{g}$ /day, with levels of more than $900 \mu \mathrm{g} /$ day causing severe toxicity [29]. In light of this, consumption of the regular three cups of SMH/71/147 infusion would be unwise. Toxic limits for $\mathrm{Mn}$ and $\mathrm{Mg}$ could not be found.

For heavy metals, the calculated intake of As was above the safety limit (0.4060 mg/day) in sample SMH/71/147 $(<6$ $\mathrm{mg}$ /day), the only infusion in which this element was detected. Calculated daily intake of $\mathrm{Hg}$ was above the safety limit in $\mathrm{SMH} / 82 / 28$; Cd was above the limits for consumption of $\mathrm{SMH} / 71 / 147, \mathrm{SMH} / 82 / 28$ and $\mathrm{SMH} / 71 / 116$ and $\mathrm{Pb}$ : $\mathrm{SMH} / 71 / 2, \mathrm{SMH} / 71 / 147$ and $\mathrm{SMH} / 82 / 28$. While these findings were not reflective of samples from all locations, it is assumed that the high levels observed in the instances identified may have been as a result of the environment from which samples were collected (near roadways in some instances), as well as soil and water quality.

\section{Phenolic Constituents of Search-Me-Heart Infusions}

Phenolics are the main classes of secondary metabolites found in plants. They are known to have a broad spectrum of bioactivity contributing to antioxidant, antimutagenic, antibacterial, anti-carcinogenic, anti-inflammatory, anti-viral, 
Table 5. Comparison of Phenolic Content of Search-Me-Heart Infusions and Two Commercial Black Teas

\begin{tabular}{|c|c|c|c|c|c|c|}
\hline \multirow[t]{2}{*}{ Samples } & \multicolumn{2}{|c|}{ Total Polyphenols Content ${ }^{\text {a }}$} & \multicolumn{2}{|c|}{ Total Flavonoids ${ }^{a}$} & \multicolumn{2}{|c|}{ Total Tannins a } \\
\hline & mg GAE / serving & $\begin{array}{l}\text { mg GAE / g } \\
\text { dry powder }\end{array}$ & mg CE / serving & $\begin{array}{c}\mathrm{mg} \mathrm{CE} / \mathrm{g} \text { dry } \\
\text { powder }\end{array}$ & mg TAE / serving & $\begin{array}{l}\text { mg TAE / g } \\
\text { dry powder }\end{array}$ \\
\hline SMH/71/2 & $41.01 \pm 1.84^{\mathrm{a}}$ & $20.42 \pm 0.93^{\mathrm{a}}$ & $30.86 \pm 0.52^{\mathrm{a}}$ & $15.43 \pm 0.26^{\mathrm{a}}$ & $42.13 \pm 1.67^{\mathrm{a}}$ & $21.07 \pm 0.84^{\mathrm{a}}$ \\
\hline SMH/71/76 & $24.45 \pm 3.56^{\text {bh }}$ & $12.19 \pm 1.79^{\text {bh }}$ & $13.61 \pm 0.14^{\mathrm{b}}$ & $6.81 \pm 0.07^{\mathrm{b}}$ & $29.20 \pm 2.87^{\mathrm{b}}$ & $14.60 \pm 1.44^{\mathrm{b}}$ \\
\hline SMH/71/116 & $62.36 \pm 1.42^{\mathrm{c}}$ & $31.05 \pm 0.65^{\mathrm{c}}$ & $42.83 \pm 1.23^{\mathrm{chi}}$ & $21.41 \pm 0.61^{\mathrm{chi}}$ & $53.67 \pm 0.71^{\mathrm{cg}}$ & $26.83 \pm 0.35^{\mathrm{cg}}$ \\
\hline SMH/71/147 & $28.48 \pm 1.51^{\mathrm{dh}}$ & $14.17 \pm 0.74^{\mathrm{dh}}$ & $15.42 \pm 0.57^{\mathrm{d}}$ & $7.71 \pm 0.28^{\mathrm{d}}$ & $21.20 \pm 0.31^{\mathrm{d}}$ & $10.60 \pm 0.15^{\mathrm{d}}$ \\
\hline SMH/82/28 & $48.07 \pm 0.31^{\mathrm{e}}$ & $23.99 \pm 0.17^{\mathrm{e}}$ & $39.23 \pm 0.86^{\mathrm{eh}}$ & $19.61 \pm 0.43^{\text {eh }}$ & $45.87 \pm 2.13^{\mathrm{a}}$ & $22.93 \pm 1.07^{\mathrm{a}}$ \\
\hline Black Tea A & $154.17 \pm 2.98^{\mathrm{f}}$ & $76.83 \pm 1.43^{\mathrm{f}}$ & $45.70 \pm 0.97^{\mathrm{fi}}$ & $22.77 \pm 0.50^{\mathrm{fi}}$ & $136.72 \pm 2.46^{\mathrm{e}}$ & $68.13 \pm 1.25^{\mathrm{e}}$ \\
\hline Black Tea B & $74.62 \pm 0.48^{\mathrm{g}}$ & $37.12 \pm 0.28^{g}$ & $17.66 \pm 0.54^{\mathrm{g}}$ & $8.78 \pm 0.26^{\mathrm{g}}$ & $55.86 \pm 0.48^{\mathrm{fg}}$ & $27.79 \pm 0.20^{\mathrm{fg}}$ \\
\hline
\end{tabular}

GAE - Gallic Acid Equivalent; CE - Catechin Equivalent; TAE - Tannic Acid Equivalent; Infusions were prepared from 1g of tea/search-me-heart powder in $100 \mathrm{~mL}$ boiling water; $\mathrm{mg} /$ serving - Values represent content of a $200 \mathrm{~mL}$ cup of tea ( $2 \mathrm{~g}$ tea/search-me-heart powder in $200 \mathrm{~mL}$ boiling water); ${ }^{2}-$ Values represent the mean of six determinations taken from three samples \pm Standard Error of Mean; ${ }^{a}$, b..... Mean values in the same column with the same letter are not significantly different $(\mathrm{p} \leq 0.05)$.

anti-allergic and immune-stimulating activities [30-33]. Teas and herbal infusions contribute to the major source of phenolic compounds in our diet [30,32]. More specifically, studies have suggested that regular consumption of some herbal teas may be potentially useful in providing protection against certain relevant oxidative species $[31,34]$. In view of the association between plant phenolics and anti-oxidant activity along with the recent thrust to market teas for their antioxidant properties, the content of total polyphenols, flavonoids and tannins were determined in search-me-heart infusions. The results are summarized in Table $\mathbf{5}$.

\section{Total Polyphenol Contents}

The total polyphenol content of search-me-heart infusions (expressed as $\mathrm{mg}$ gallic acid equivalent / $\mathrm{g}$ dry powder) were derived from a gallic acid standard curve ranging from $0.02-0.1 \mathrm{mg} / \mathrm{mL}\left(\mathrm{R}^{2}=0.9989\right)$. There was significant variation in the total polyphenol content among three of the samples, the exceptions being SMH/71/76 and SMH/71/147, which were not significantly different. Quantities of total polyphenols ranged from $12.19 \pm 1.79 \mathrm{mg} / \mathrm{g}$ to $31.05 \pm 0.65$ $\mathrm{mg} / \mathrm{g}$ and decreased in the following order: $\mathrm{SMH} / 71 / 116>$ $\mathrm{SMH} / 82 / 28>\mathrm{SMH} / 71 / 2>\mathrm{SMH} / 71 / 147>\mathrm{SMH} / 71 / 76$. The differences in levels of total polyphenol between the commercial black teas were also significant. In comparing the commercial teas with the search-me-heart infusions, it was observed that whereas the level of total polyphenols in the Black Tea B (37.12 $\pm 0.28 \mathrm{mg} / \mathrm{g})$ was comparable (albeit significantly different) to the search-me-heart infusion with the highest content of total polyphenol (SMH/71/116 - 31.05 $\pm 0.65 \mathrm{mg} / \mathrm{g})$, the level in Black Tea A $(76.83 \pm 1.43 \mathrm{mg} / \mathrm{g})$ was three times that in all the infusions except SMH/71/116. The results are not surprising since levels of total polyphenols up to $124 \mathrm{mg}$ of gallic acid equivalent have been re- ported for black teas [35]. It is important to note that Black Tea B contained plant material other than Camelia sinensis, hence total polyphenol content was understandably not as high as the unblended Black Tea A. The total polyphenol content available per serving (Table 5), suggests that an average daily intake of two - three cups of the search-me-heart infusion (current consumption pattern for herbal teas) would be required in order to obtain similar polyphenol-related benefits as per cup of Black Tea A.

\section{Total Flavonoid Content}

Total flavonoid content (expressed as $\mathrm{mg}$ catechin equivalent/g dry powder) were derived from a catechin standard curve in the range of $20-100 \mathrm{mg} / \mathrm{L}\left(\mathrm{R}^{2}=0.9996\right)$. Quantities of total flavonoids ranged from $6.81 \pm 0.07 \mathrm{mg} / \mathrm{g}$ to $21.41 \pm 0.61 \mathrm{mg} / \mathrm{g}$ and decreased in the order of: $\mathrm{SMH} / 71 / 116>\mathrm{SMH} / 82 / 28>\mathrm{SMH} / 71 / 2>\mathrm{SMH} / 71 / 76>$ $\mathrm{SMH} / 71 / 147$ (Table 5). Whereas significant variations in total flavonoid contents were observed for $\mathrm{SMH} / 71 / 2$, $\mathrm{SMH} / 71 / 76$ and $\mathrm{SMH} / 71 / 147$, contents were not significantly different for SMH/71/116 and $\mathrm{SMH} / 82 / 28$. As was observed for total polyphenols, total flavonoid contents of the commercial black teas were also significantly different (Black Tea A - $22.77 \pm 0.50 \mathrm{mg} / \mathrm{g}$ versus Black Tea B -8.78 $\pm 0.26 \mathrm{mg} / \mathrm{g}$ ). However, of importance is the fact that the total flavonoid content for infusion SMH/71/116 (21.41 \pm $0.61 \mathrm{mg} / \mathrm{g}$ ) was not significantly different from that of the Black Tea A $(22.77 \pm 0.50 \mathrm{mg} / \mathrm{g})$, suggesting that this could be a key factor in positioning the herbal infusion in the herbal teas market. In comparing the total flavonoid content available per serving for Black Tea A $(45.70 \pm 0.97$ $\mathrm{mg} / \mathrm{serving}$ ) obtained from this investigation with the value used in marketing the tea $(175 \mathrm{mg} / \mathrm{serving}$ - reported on packaging), it becomes obvious that the differences are quite 
significant. However, this could have been due to differences in the methods of determination, as well as the selection of calibration standard (eg. rutin, catechin, epicatechin) used for expression of the results. Variations are however not unusual since other levels of total flavonoids have also been reported in the literature for black teas like sample A eg. $17.5 \mathrm{mg} \mathrm{ru}-$ tin /g tea leaves [36].

\section{Total Tannins Content}

Tannins are natural compounds that abound in herbs, wood and fruits [37]. They are responsible for the colour, strength and characteristic astringent taste of teas and herbal infusions. They are however considered undesirable because they precipitate protein, inhibit digestive enzymes and affect the utilization of vitamins and minerals/elements [38]. The content of total tannins in search-me-heart infusions, being critical to these effects was thus determined. Data obtained for total content of search-me-heart infusions and the two commercial black teas are presented in Table $\mathbf{5}$.

Quantities of total tannins ranged from $10.6 \pm 0.15 \mathrm{mg} / \mathrm{g}$ to $26.83 \pm 0.35 \mathrm{mg} / \mathrm{g}$ and decreased in the following order: $\mathrm{SMH} / 71 / 116>\mathrm{SMH} / 82 / 28>\mathrm{SMH} / 71 / 2>\mathrm{SMH} / 71 / 76>$ $\mathrm{SMH} / 71 / 147$. Significant differences were observed in tannin content of infusions from all locations except SMH/71/2 $(21.07 \pm 0.84 \mathrm{mg} / \mathrm{g})$ and $\mathrm{SMH} / 82 / 28(22.93 \pm 1.07 \mathrm{mg} / \mathrm{g})$ which were not significantly different at $\mathrm{p} \leq 0.05$. Quantities of total tannins in the Black Tea A and Black Tea B were significantly different from each other at $68.13 \pm 1.25 \mathrm{mg} / \mathrm{g}$ and $27.79 \pm 0.20 \mathrm{mg} / \mathrm{g}$ respectively, and from the search-meheart infusions. The infusion of SMH/71/116 was the exception, being found not to differ significantly from the Black Tea B. It is important to note that the search-me-heart infusions contained significantly lower quantities of total tannins than the commercial black teas. These results were as expected, since tea (Camelia sinensis) is known to contain naturally high levels of tannins linked to the content of catechins and other flavonoids [39]. Values between $4.8 \mathrm{mg} / \mathrm{g}$ and $55.7 \mathrm{mg} / \mathrm{g}$ total tannins have reported in literature for Black Tea A $[36,38]$. In examining the total tannin available per serving (Table 5) of tea and search-me-heart infusions, it would appear based on tannin content, that the consumption of search-me-heart infusions would be a healthier alternative to the two black teas, but more so Black Tea A and could be used as another key parameter for positioning the herbal tea. However, caution should be exercised in this regard since there may be other compounds present in search-me-heart which may have other adverse effects. Toxicological studies of search-me-heart are therefore advised. It was also observed that $\mathrm{SMH} / 71 / 116$, which contained the highest amount of total polyphenols and flavonoid compounds, also contained the highest levels of tannins, suggesting that there may be some direct correlation among these three compounds.

\section{Total Antioxidant Activity of Search-Me-Heart Infusions}

An antioxidant is any substance which at low concentrations compared to that of an oxidizable substrate (eg. DNA, lipid or carbohydrate) significantly delays or inhibits the oxidation of that substrate, thus preventing damage to cellular components due to chemical reactions involving free radicals $[30,40]$. Free radicals conversantly are reactive oxygen species (ROS) that contribute to aging and degenerative diseases eg. cancer, cardiovascular disease among others. The main characteristic of an antioxidant is therefore its ability to trap or scavenge free radicals. Antioxidant compounds like phenolic acids, polyphenols and flavonoids are mainly supplied as dietary consumptions eg. herbal teas, hence it was important to evaluate the in vitro antioxidant capacity of the search-me-heart infusions, in order to determine the health-promoting benefits of the herbal tea. In the present study, three different antioxidative methods were used to examine the activity of search-me-heart infusions from five locations across Jamaica. The DPPH assay which measures the disappearance of the free radical $\mathrm{DPPH}^{+}$, the TEAC assay which is linked to the disappearance of the $\mathrm{ABTS}^{+}$and the $\mathrm{F}-\mathrm{C}$ reducing capacity assay which measures the ability of samples to reduce the yellow F-C reagent to dark blue were the methods used. This is because different antioxidant compounds may act in vitro through different mechanisms; hence no single method can be used to fully evaluate antioxidant capacity. Table $\mathbf{6}$ summarizes the results of each assay.

\section{DPPH Assay}

The DPPH radical has been widely used as a model to investigate the scavenging activities of several natural compounds including phenolic compounds, flavonoids or crude mixtures such as ethanol or water extracts of plants [40]. DPPH is a stable free radical with a purple colour, which is scavenged by antioxidants through the donation of a hydrogen atom or an electron. This results in the formation of the reduced DPPH-H (1, 1 diphenyl-z-picrylhydrazine) which is yellow or colourless and can be quantified by its decrease in absorbance at $517 \mathrm{~nm}[31,40]$. Fig. (4) shows the DPPH antioxidant activity of search-me-heart infusions and that of the two commercial teas. Antioxidant activity of the infusions decreased in the following order: $\mathrm{SMH} / 71 / 116>$ $\mathrm{SMH} / 82 / 28>\mathrm{SMH} / 71 / 76>\mathrm{SMH} / 71 / 147>\mathrm{SMH} / 71 / 2$ and ranged between $59.57 \pm 4.25 \%-84.49 \pm 0.71 \%$. The antioxidant activity of infusion SMH/71/116 (84.49 $\pm 0.71 \%)$ was not significantly different from that of $\mathrm{SMH} / 82 / 28$ $(84.08 \pm 0.16 \%)$. There were also no significant differences in antioxidant activity of the other three infusions. The two commercial black teas; Black Tea A and Black Tea B had similar activities; $87.83 \pm 0.26 \%$ and $88.22 \pm 0.39 \%$ respectively and were not significantly different from SMH/71/76 $(66.22 \pm 9.98 \%)$. However, the latter observation may have been related to the large standard error of the mean in $\mathrm{SMH} / 71 / 76$.

\section{Folin-Ciocalteu (F-C) Reducing Capacity Assay}

The $\mathrm{F}-\mathrm{C}$ reducing capacity is an electron transfer based assay which measures the ability of the extracts (antioxidants) to reduce the chromagen compound phosphomolybdic-tungstic of the F-C reagent [41-43]. Under basic conditions, phenolic groups are deprotonated leading to a phenolic anion with reducing potential. F-C reagent is thought to be a phosphomolybdate-phosphotungstate complex. It is believed that the molybdenum in the complex Mo (VI) has the characteristic yellow colour which upon reduction to Mo (V) phenolate anions becomes blue [43]. The reaction equation can be summarized as follows [42]: 
Table 6. Comparison of Antioxidant Activity of Search-Me-Heart Infusions by Different Methods.

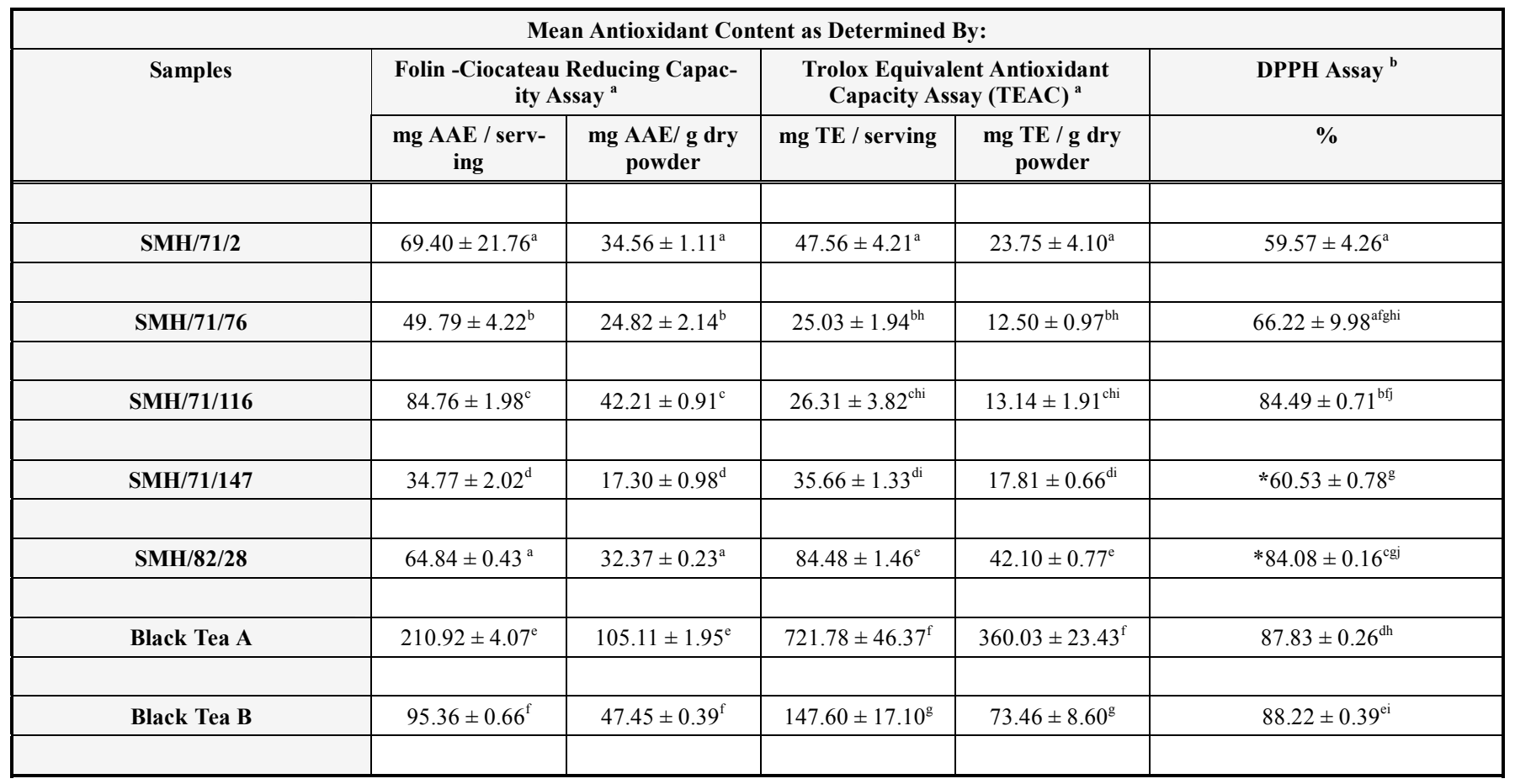

AAE - Ascorbic Acid Equivalent;TE - Trolox Equivalent; Infusions were prepared from $1 \mathrm{~g}$ of tea in $100 \mathrm{~mL}$ boiling water; $\mathrm{mg} / \mathrm{serving}$ - Values represent content of a $200 \mathrm{~mL}$ cup of tea ( $2 \mathrm{~g}$ tea/search-me-heart powder in $200 \mathrm{~mL}$ boiling water); ${ }^{\mathbf{a}, ~}{ }^{*}-$ Values represent the mean of six determinations taken from three samples \pm Standard Error of Mean; ${ }^{\mathbf{b}}-$ Values represent the mean of four determinations taken from two samples \pm Standard Error of Mean; ${ }^{a}, \mathrm{~b}$...... Mean values in the same column with the same letter are not significantly different $(\mathrm{p} \leq 0.05)$.

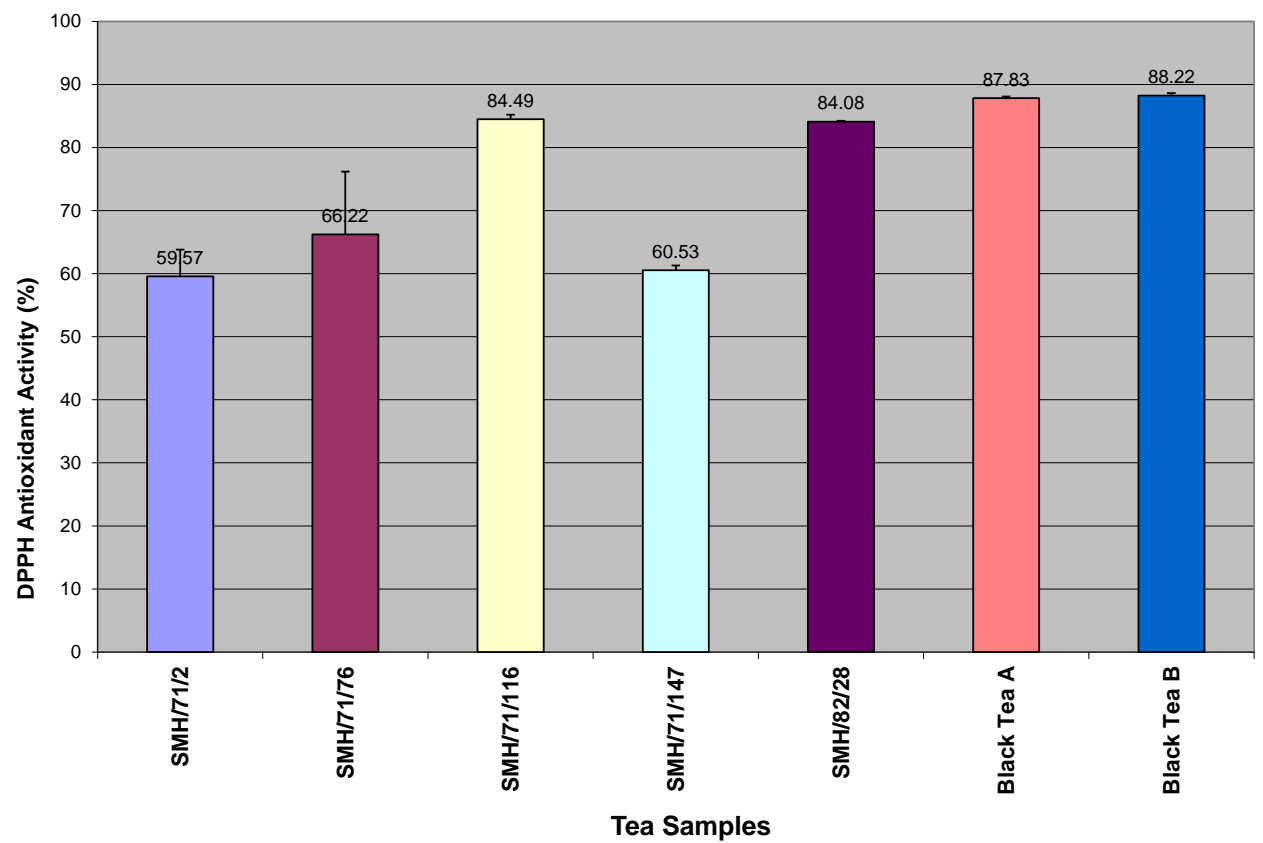

Fig. (4) DPPH Antioxidant Activity (\%) in Search-Me-Heart Infusions from 5 Locations Compared to Two Commercial Black Teas SMH/71/2 - Location 1, SMH/71/76 - Location 2, SMH/71/116 - Location 3, SMH/71/147 - Location 4, SMH/82/28 - Location 5, Black Tea A - Commercial Tea, Black Tea B - Commercial Tea.

Folin: Mo (VI) (yellow) $+\mathrm{e}^{-}$(from AH) $\rightarrow$ Mo (V) (blue)

$\lambda \max =765 \mathrm{~nm}, \mathrm{AH}$ refers to the antioxidant.

The F-C reducing capacities of the search-me-heart infusions were derived from an ascorbic acid standard curve in the range of $0.02-0.1 \mathrm{mg} / \mathrm{mL}\left(\mathrm{R}^{2}=0.9997\right)$. Data obtained for the infusions and commercial teas are summarized in Fig. (5).

Reducing capacities of the infusions decreased in the order of: $\mathrm{SMH} / 71 / 116>\mathrm{SMH} / 71 / 2>\mathrm{SMH} / 82 / 28>$ $\mathrm{SMH} / 71 / 76>\mathrm{SMH} / 71 / 147$ ranging between $17.30 \pm 0.9$ $\mathrm{mg} / \mathrm{g}$ and $42.21 \pm 0.91 \mathrm{mg} / \mathrm{g}$. Ascorbic acid has been reported to be a potent reducing agent with strong radical 


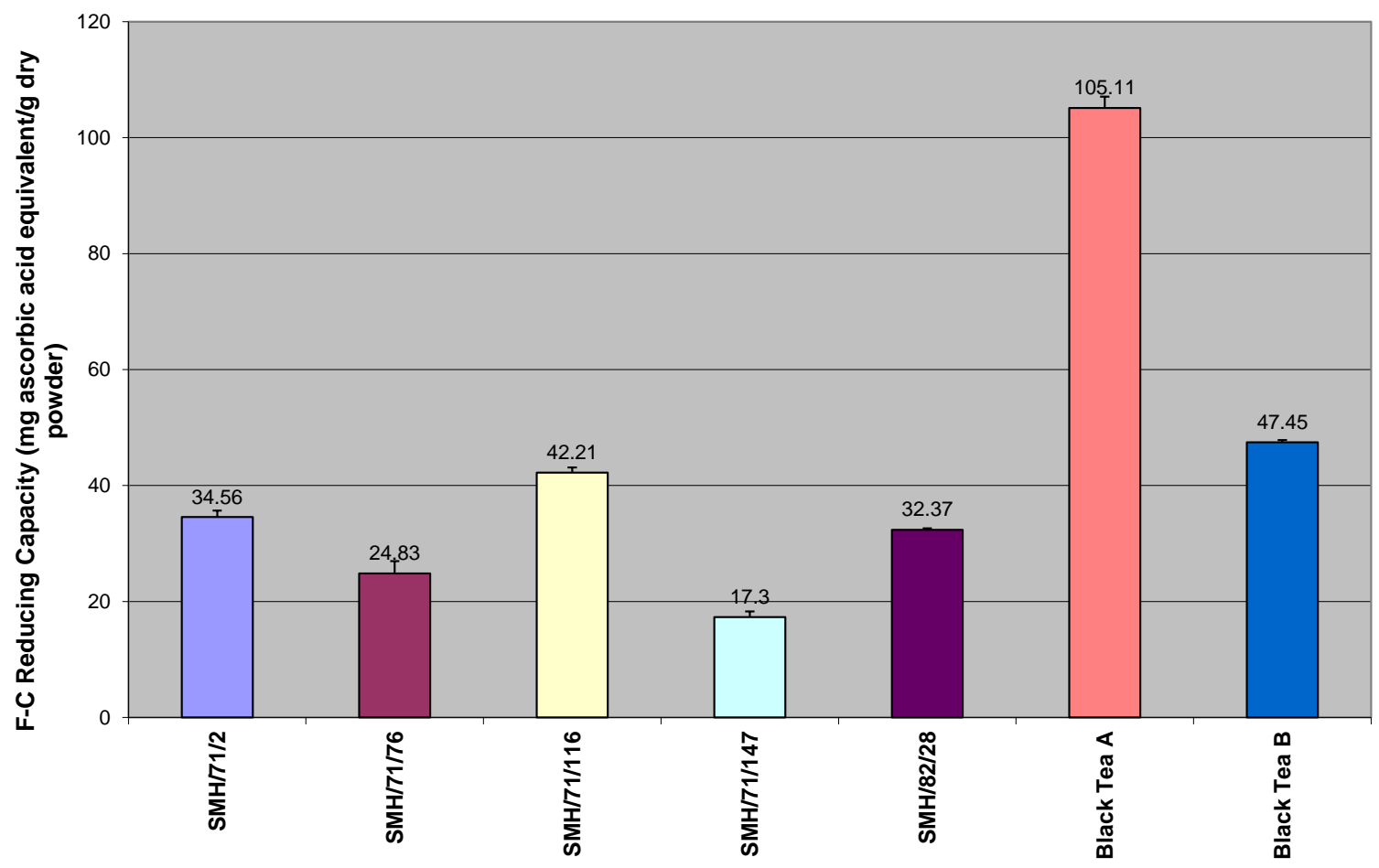

Tea Samples

Fig. (5) Folin-Ciocalteau Reducing Capacities of Search-Me-Heart Infusions from 5 Locations Compared to Two Commercial Black Teas SMH/71/2 - Location 1, SMH/71/76 - Location 2, SMH/71/116 - Location 3, SMH/71/147 - Location 4, SMH/82/28 - Location 5, Black Tea A - Commercial Tea, Black Tea B - Commercial Tea.

scavenging ability [44], hence it may be assumed that the values obtained were reflective of the reducing capacities of the various infusions. On the other hand however, it should be noted that ascorbic acid has low thermal resistance [45], which may have resulted in lowered reducing capacities, since infusions were prepared using boiling water. Significant differences were observed in the reducing capacities of infusions from all locations except infusions SMH 71/2 $(34.56 \pm 1.11 \mathrm{mg} / \mathrm{g})$ and $\mathrm{SMH} / 82 / 28(32.37 \pm 0.23 \mathrm{mg} / \mathrm{g})$ (Table 6). The commercial black teas also had significantly different reducing capacities when compared with each other (Black Tea A - $105.11 \pm 1.95 \mathrm{mg} / \mathrm{g}$ vs. Black Tea B - 47.45 $\pm 0.39 \mathrm{mg} / \mathrm{g}$ ), as well as the search-me-heart infusions.

\section{TEAC Assay}

The TEAC assay is based on the ability of antioxidant molecules to quench the long-lived $\mathrm{ABTS}^{+}$, a blue-green chromophore with characteristic absorption at $734 \mathrm{~nm}$, compared with that of Trolox, a water-soluble Vitamin E analog. The addition of antioxidants to the preformed radical cation reduces it to ABTS, determining a decolourization [46]. The reaction equation can be summarized as follows [42]: $734 \mathrm{~nm}$

$$
\text { ABTS/TEAC: ABTS }+\mathrm{K}_{2} \mathrm{~S}_{2} \mathrm{O}_{8} \rightarrow \mathrm{ABTS}^{+} \text {(1) } \lambda \text { max }=
$$

$$
\mathrm{ABTS}^{+}+\mathrm{ArOH} \rightarrow \mathrm{ABTS}+\mathrm{ArO}+\mathrm{H}^{+}
$$

Where ABTS: 2, 2 azino-bis (3-ethylbenzothiazoline-6sulfonic acid), TEAC is Trolox-equivalent antioxidant ca- pacity (name of the assay) and $\mathrm{ArOH}$ is the antioxidant compound.

TEAC values were determined using a trolox standard curve prepared in the range of $0.2-1 \mathrm{mM}\left(\mathrm{R}^{2}=0.9913\right.$. Total antioxidant capacity of the search-me-heart infusions ranged from $12.50 \pm 0.97 \mathrm{mg} / \mathrm{g}$ to $42.10 \pm 0.77 \mathrm{mg} / \mathrm{g}$, decreasing in the order of: $\mathrm{SMH} / 82 / 28>\mathrm{SMH} / 71 / 2>$ $\mathrm{SMH} / 71 / 147>\mathrm{SMH} / 71 / 116>\mathrm{SMH} / 71 / 76$ (Table 6, Fig. 6). The antioxidant capacity of infusions $\mathrm{SMH} / 71 / 2$ and $\mathrm{SMH} / 82 / 28$ were found to be significantly different from the other three samples, with the latter having about three times the capacity of the sample with the lowest antioxidant capacity. Black Tea A $(360.03 \pm 23.43 \mathrm{mg} / \mathrm{g})$ had almost five times the antioxidant capacity of Black Tea B (73.46 \pm 8.60 $\mathrm{mg} / \mathrm{g})$. Both were also significantly different from the search-me-heart infusions. Examination of the antioxidants per serving (Table 6) indicated an extremely high value of $721.78 \pm 46.37 \mathrm{mg} / \mathrm{g}$ for Black Tea A, five times greater than the total antioxidant value of $135 \mathrm{mg}$, reported on the product package and possibly an overestimation.

\section{Correlation between Antioxidant Activity and Total Polyphenols, Flavonoids and Tannins}

A regression model was used to determine the relationship between the antioxidant activity and each phenolic constituent for each of the three antioxidant methods used. Additionally, the pair-wise relationships of the three methods were determined. The relationship between the total tannins and the antioxidant methods are summarized in Fig. (7a). A 


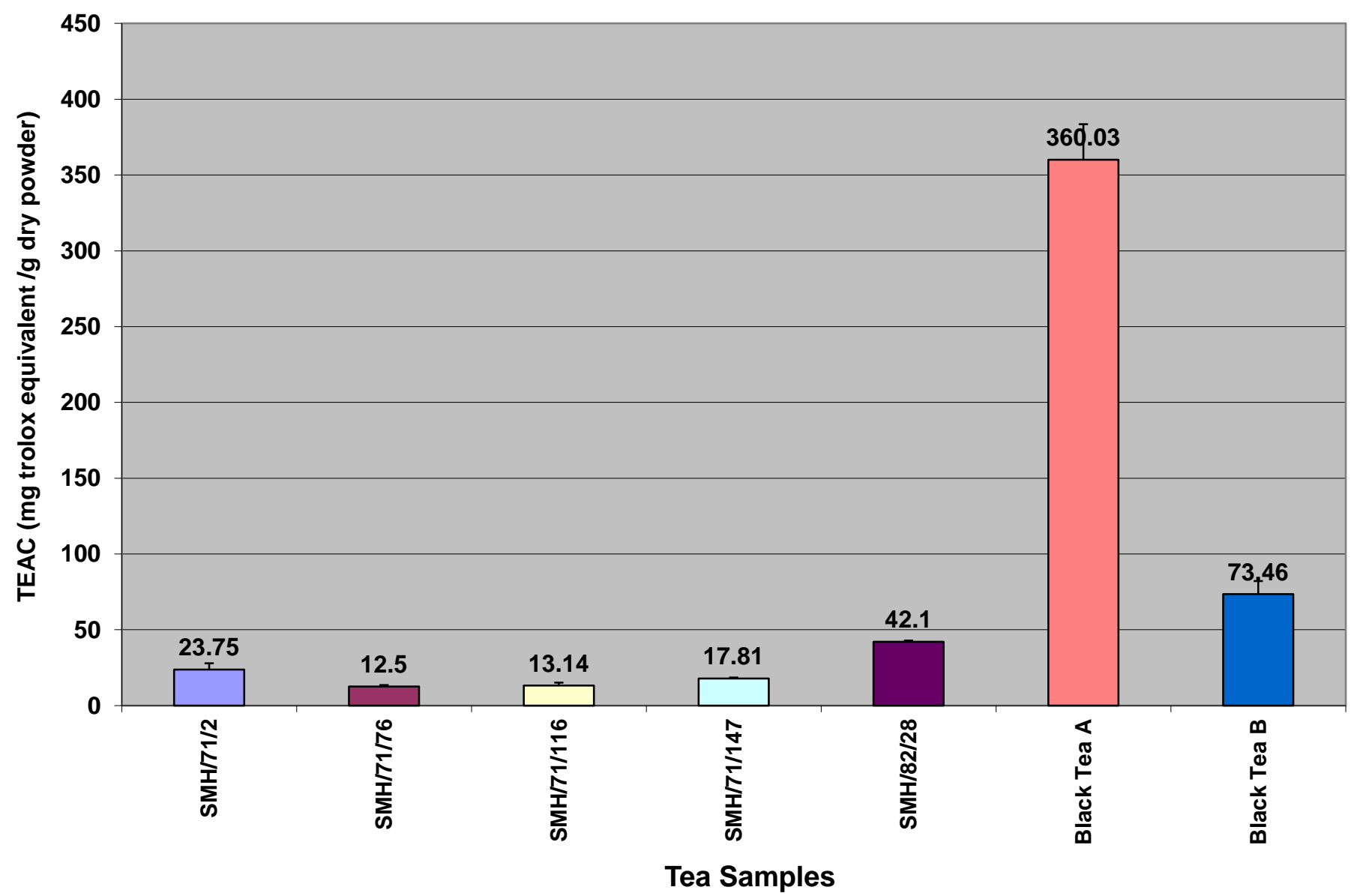

Fig. (6) Trolox Equivalent Antioxidant capacity of Search-Me-Heart Infusions from 5 Locations Compared to Two Commercial Black Teas. SMH/71/2 - Location 1, SMH/71/76 - Location 2,

SMH/71/116 - Location 3, SMH/71/147 - Location 4, SMH/82/28 - Location 5, Black Tea A - Commercial Tea, Black Tea B - Commercial Tea.

significant relationship was observed between total tannins and antioxidant activity by the F-C reducing capacity assay $\left(\mathrm{R}^{2}=0.9563\right)$, with weaker correlations of $\mathrm{R}^{2}=0.5584$ and 0.0806 between total tannins and the DPPH and TEAC assays respectively. Similar trends were observed for correlations between total polyphenols, total flavonoids and antioxidant activity (Figs. $\mathbf{7 b}$ and $7 \mathbf{c}$ ). Overall results indicate that the F-C reducing capacity assay may be most suitable for determination of antioxidant activities in search-me-heart infusions, based on the high correlation coefficients obtained, followed by DPPH assay, with TEAC assay being the least effective in determining antioxidant activity. The F-C reducing capacity assay, is however not an absolute measurement of the amount of phenolic materials, since different types of phenolic compounds have different antioxidant activities depending on their structures $[30,47]$, hence caution should be observed in limiting determination of antioxidant activity to a single assay. Correlation of the parameters examined to antioxidant activity determined by the F-C reducing capacity assay was also observed to decrease in the following order: total tannins $\left(\mathrm{R}^{2}=0.9563\right)>$ total polyphenols
$\left(\mathrm{R}^{2}=0.802\right)>$ total flavonoids $\left(\mathrm{R}^{2}=0.7911\right)$. All had relatively strong correlation coefficients, an indication that all three groups of compounds may be contributing significantly to the antioxidant activity. However, results suggest that contribution by tannins to the antioxidant activity of searchme-heart infusions is greater than the other compounds. While, this may be a deviation from the norm, having been suggested in several studies that there exists a causative relationship between total polyphenol content and antioxidant activity [40, 48], it is not surprising, since the antioxidant activities of tannins have also been well documented [38, 47]. The overall poor correlation of all phenolic constituents with TEAC suggest that these compounds might not be capable of scavenging the ABTS ${ }^{+}$free radical.

Figs. (8a-c) represent the pairwise relationships of the antioxidant methods used. Low correlation values were observed in comparing each pair of methods, suggesting that there may be a mechanism by which the phenolics in the extracts scavenge the radicals thus making identification of any one method difficult. It should also be noted that the overall results may also have been affected by the fact that 


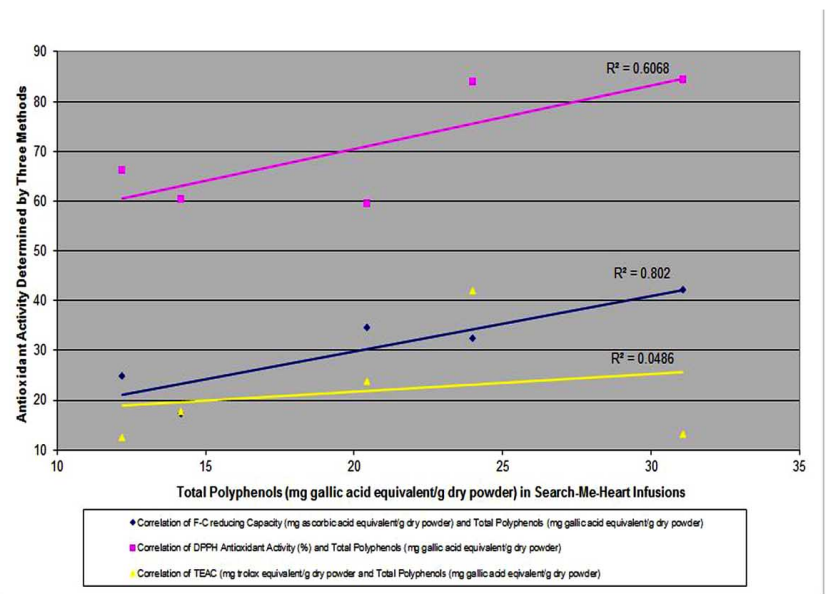

(a)

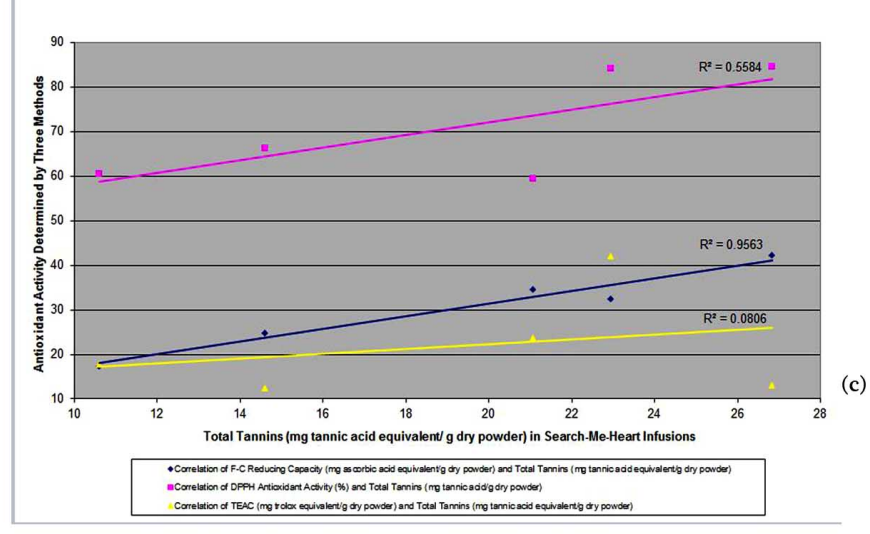

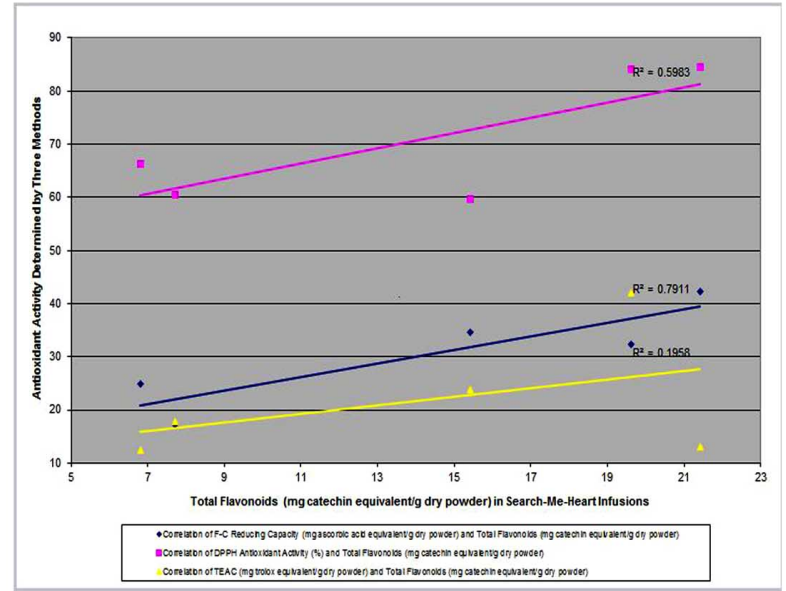

(b)

Fig. (7a-c). Correlation between Total Polyphenols (a), Total Flavonoids (b) and Total Tannins (c) in Search-Me- Heart Infusions and Antioxidant Methods.

the radicals are dissimilar in nature. The F-C method measures free acid bound hydrophilic antioxidants, producing strong reactions with compounds such as phenol and coumaric acid. DPPH measures free hydrophobic antioxidants only and cannot detect compounds like gallic and tannic acids. Additionally, other compounds which also absorb at 517 $\mathrm{nm}$ may interfere with the DPPH assay, leading to an underestimation of antioxidant activity. The TEAC assay measures hydrophobic antioxidants with the lack of correlation to other assays being attributable to an underestimation of overall antioxidant capacity related to dilution effects as well as phenolic measurement of inhibition percentage [42, 45, $49,50]$. The combined effects of the different antioxidants, including phenolic constituents therefore has to be taken into account.

\section{Sensory Analysis}

Results of the sensory analysis of search-me-heart herbal tea are summarized in Fig. (9). There were no significant differences $(p \leq 0.05)$ in all the attributes evaluated when samples of both strengths were compared. Infusions were of moderate liking. Overall results suggest that the minimum, one gram of milled search-me-heart powder versus two grams could be packaged for sale as tea bags and still enjoy consumer acceptance.

\section{CONCLUSIONS}

Search-me-heart herbal tea has the potential to offer a new and exotic taste, along with great nutraceutical value in the functional teas segment of the beverage market. It provides the added benefit of being a good source of polyphenols which exhibit important antioxidant behavior, as confirmed by the current study. Infusions prepared with samples from the five locations studied, contained considerable amounts of polyphenolic substances and had significant antioxidant activity. The total flavonoid content of search-meheart herbal tea from at least one of the locations was not significantly different from that of Black Tea A and was greater than that of Black Tea B, suggesting that the herbal infusion could offer similar and in some instances far greater antioxidant protection with respect to flavonoid contribution than that offered by well-known commercial black teas. Overall results suggest that search-me-heart herbal tea could be an effective natural antioxidant with potential as a dietary herbal supplement, and could possibly contribute to the maintenance and promotion of good health. In order to fully realize the nutraceutical potential of search-me-heart as a functional herbal tea however, a more comprehensive characterization of the water soluble polyphenolic compounds involving quantitative HPTLC as well as HPLC-MS will need to be conducted for purposes of standardization. Additionally, the bioavailability of the bioactives, herb-drug in- 

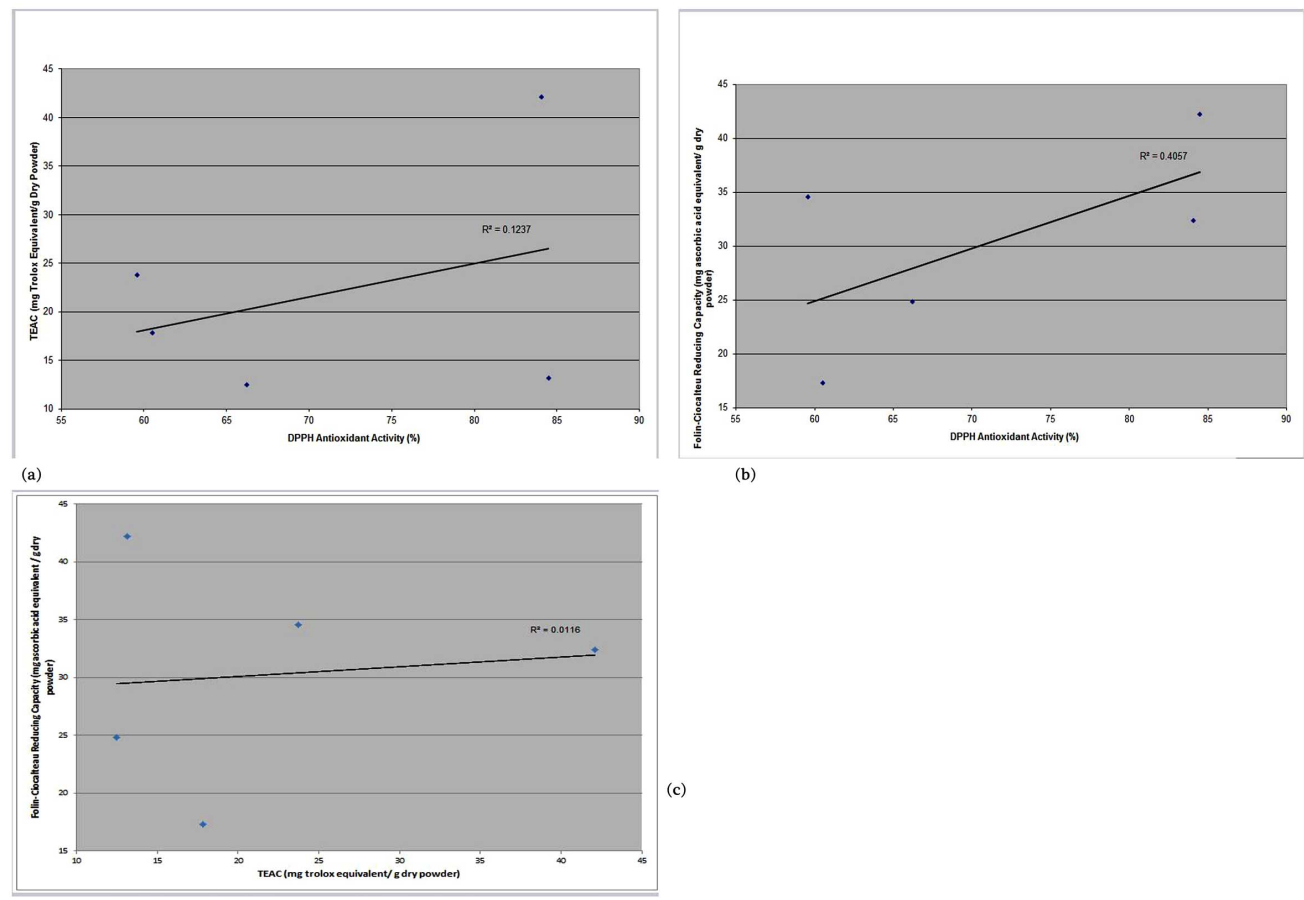

(b)

Fig. (8a-c). Correlation between Pairs of Antioxidant Methods: (a) Folin-Ciocalteau \& TEAC; (b) Folin-Ciocalteau \& DPPH; (c) TEAC \& $\mathrm{DPPH}$

teractions, as well as toxicity studies (short term) should be considered in order to ensure product safety and efficacy. Domestication or cultivation of the herb will also be necessary since the market will be limited by the fact that the plant is wild-crafted.

\section{ACKNOWLEDGEMENTS}

The authors would like to acknowledge contributions made by the Rural Agricultural Development Authority

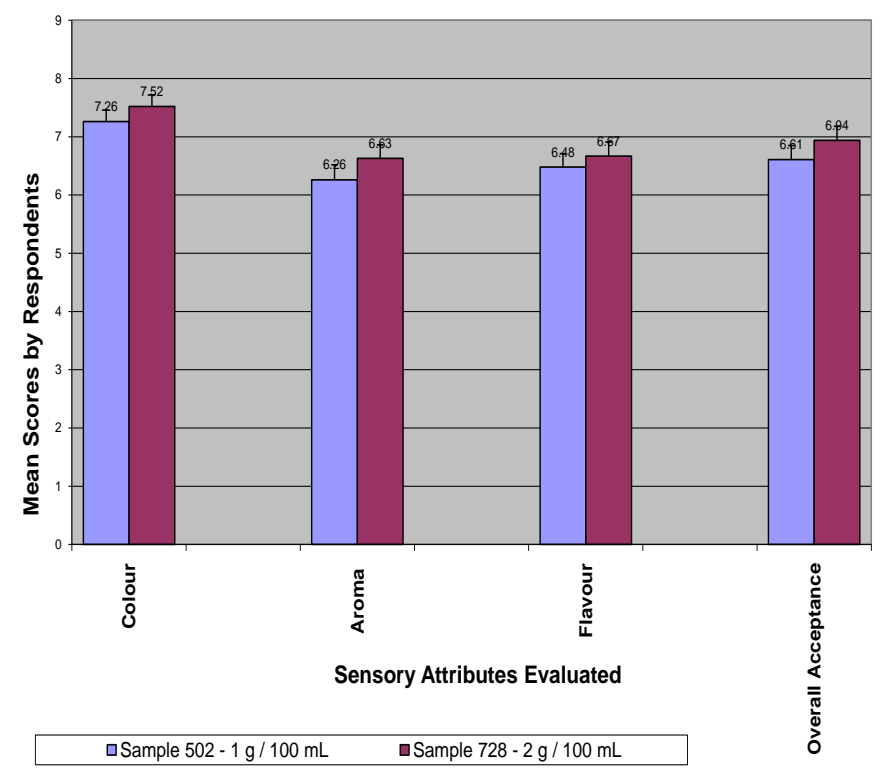

Fig. (9). Comparative Sensory Attribute Rating of Search-Me-Heart Herbal Tea Samples Prepared at Two Strengths.
(RADA) field extension officers and the farmers who played a major role in sourcing and reaping search-me-heart plant material from across the island. Our heartiest gratitude also to the research analysts of the Analytical Services Department of the Scientific Research Council for analyses conducted.

\section{CONFLICT OF INTEREST}

None declared.

\section{ABBREVIATIONS}

$$
\begin{array}{lll}
\text { DPPH } & = & \text { 2,2-Diphenyl-1-picryl-hydrazyl } \\
\text { F-C } & = & \text { Folin-Ciocalteu } \\
\text { HPTLC } & = & \text { High performance thin layer chromatogra- } \\
& = & \text { Rhy } \\
\text { ROS } & = & \text { Trolox Equivalent Antioxidant Capacity } \\
\text { TEAC } & = & 2,2 \text { 'azinobis-3-ethylbenzothiazoline-6- } \\
\text { ABTS } & = & \text { Sulfonic acid } \\
\text { WHO } & = & \text { Gallic acid equivalent } \\
\text { GAE } & = & \text { Catechin equivalent } \\
\text { CE } & = & \text { Tannic acid equivalent } \\
\text { TAE } & = & \text { Analysis of Variance } \\
\text { ANOVA } &
\end{array}
$$

\section{REFERENCES}

[1] CBI Market Information Database. Coffee, Tea and Cocoa. CBI Market Survey: The EU Market for Herbal Infusion pp.18. Available from: URL:www.cbi.eu. or http://www.cadexco.bo/- 
actual/boletininteligencia/2008\%20Herbal\%20infusions.pdf $\quad$ [accessed May26, 2009].

[2] European Medicines Agency (EMEA). Glossary on herbal teas. EMA/HMPC/5829/2010. Available from: http://www.ema.europa.eu/docs/-en_GB/document_library/Regulatory_and_procedural_guideline/2010/04/WC500089943.pdf [accessed May 19, 2009].

[3] European Herbal Infusions Association (EHIA). Compendium of Guidelines for Herbal and Fruit Infusions and Products Thereof. EHIA, Hamburg, Germany. Available from: http://www.ehiaonline.org/publicat-ions.html [accessed September 9, 2011].

[4] Lad, V.; Frawley, D. In: the yoga of herbs: an ayurvedic guide to herbal medicine - beverage teas for the three doshas. $2^{\text {nd }}$ Ed. Lotus Press, Wisconsin, USA, 1986; Appendix 1.

[5] Blumenthal, M.; Busse, W.R.; Goldberg, A.; Gruenwald, J.; Hall, T.; Riggins, C.W.; Rister, R.S. Market Conditions and Regulatory Climate for Herbs in the United States. In: the complete german commission E monographs: Therapeutic guide to herbal medicines - Published in Cooperation with Integrative Medicine Communications, Boston, Massachussetts, 1998. pp. 10.

[6] Naithani, V.; Kakkar, P. Evaluation of heavy metals in indian herbal teas. Bull. Environ. Contam. Toxicol., 2005, 75, 197-203.

[7] Marete, E.N.; Jacquier, J-C.; O'Riordan, D. Feverfew as a source of bioactives for functional foods: Storage stability in model beverages. J. Funct. Foods., 2011, 3, 38-43.

[8] Meeks-Gardener, J.; Grant, D.; Hutchinson, S.; Wilks, R. The use of herbal Teas and remedies in jamaica. W. Indian Med. J., 2000, 49(4), 331-335.

[9] Michie, C.A. The use of herbal remedies in jamaica. Ann. Trop. Paediatr., 1992, 12, 31-36.

[10] Mitchell, S.A.; Ahmad, M.H. A review of medicinal plant research at the university of the West Indies, Jamaica. W. Indian Med.J., 2006, 55(4), 243-269.

[11] Thomas, M.C.; Payne-Jackson, A. An introduction to jamaican folk medicine. Available from: http://www.gs.howard.edu/monair/scholars/-cohort-199899/04thomas.htm [accessed May 26, 2009].

[12] Adams, C.D. Gesneriaceae: Rytidophyllum. In: flowering plants of jamaica. University of the West Indies, Jamaica, 1972, pp. 682.

[13] Morton, J.F. Atlas of medicinal plants of middle america. C.C. Thomas Publishers Ltd., Springfield, Illinois, 1981, pp.1420.

[14] Facey, P.C.; Pascoe, K.O.; Porter, R.B.; Jones, A.D. Investigation of plants used in jamaican folk medicine for anti-bacterial activity. J. Pharm. Pharmacol., 1999, 51, 1455-1460.

[15] Rapavi, E.; Szentmihályi, K.; Lugasi, A.; Vági, E.; Bányai, É.; Balázs, A.; Szöke, É.; Blázavics, A. The influence of the steeping time in the antioxidant properties of a chinese herbal tea. Acta Alimetaria, 2006, 35(2), 213-222.

[16] Eaton, A.D.; Clesceri, L.S.; Rice, E.W.; Greenberg, A.E. (Eds.). In: standard methods for examination of water and wastewater, $21^{\mathrm{st}}$ ed.; American Public Health Association, American Water Works, American Environment Federation. Port City Press, Baltimore, Maryland, USA, 2008.

[17] Marinova, D.; Ribarova, F.; Atanassova, M. Total phenolics and total flavonoids in bulgarian fruits and vegetables. J. Univ. Chem. Technol. Metallurgy, 2005, 40, 255-260.

[18] Rajpal, V. Testing procedure of tannins (by U.S.S.R.P. method) in terminalia chebula fruit (Harir) extract. In: Standardization of botanicals; eastern publishers, New Delhi, India, 2005, V2, pp. 342-343.

[19] Williams, L.A.D.; Hibbert, S.L.; Porter, R.B.R.; Bailey-Shaw, Y.A.; Green, C.E. Jamaican plants with in vitro anti-oxidant activity. In: biologically active natural products for the $21^{\text {st }}$ century. L.A.D. Williams (Ed.) Research Signpost, Trivandrum, India, 2006, pp. 1-12.

[20] Sharma, N.K.; Dey, S.; Prasad, R. In vitro antioxidant potential evaluation of euphorbia hirtia L. Pharmacologyonline, 2007, 1, 91-98.

[21] Meilgaard, M.; Civille, G.V.; Carr, B.T. Sensory Evaluation Techniques, $3^{\text {rd }}$ edition; CRC Press, Inc., Boca Raton, Fla. 33431, 1999.

[22] Poste, L.M.; Mackie, D.A.; Butler, G.; Larmond, E. Laboratory methods for sensory analysis of food; Agriculture Canada, Vol. IV, 1991.

[23] Özcan, M. Determination of Mineral Contents of Turkish Herbal Tea (Salvia aucheri var. canescens) at Different Infusion Periods. J. Med. Food, 2005, 8(1), 110-112.
[24] Nookabkaew, S.; Rangkadilok, N.; Satayavivad, J. Determination of trace elements in herbal tea products and their infusions consumed in Thailand. J. Agric. Food Chem., 2006, 54(18), 69396944.

[25] Karimi, G.; Hasanzadeh, M.K.; Nili, A.; Khashayarnanesh, Z.; Samiei, Z.; Nazari, F.; Teimuri, M. Concentrations and health risk of heavy metals in tea samples marketed in Iran. Pharmacologyonline, 2008, 3, 164-174.

[26] WHO (World Health Organization). Evaluation of Certain Food Additives and Contaminants. WHO Technical Report Series 776, World Health Organization (WHO), Geneva, Switzerland, 1989.

[27] World Health Organization (WHO). Determination of arsenic and heavymetals. In: quality control methods for medicinal plant materials; World Health Organization (WHO), Geneva, Switzerland, 1998, pp. 61-63.

[28] Food and Drug Administration (FDA). Action level for methylmercury in fish; US Food and Drug Administration, Washington, D.C., 1984, Federal Register 49, 45663.

[29] Caribbean Food and Nutrition Institute (CFNI). Recommended Dietary Allowances for the Caribbean. Report of the Committee of the Expert Group on Caribbean Food and Nutrition Surveillance System. CFNI, Kingston, Jamaica, 1994.

[30] Atoui, A.K.; Mansouri, A.; Boskou, G.; Kefalas, P. Tea and herbal infusions: their antioxidant activity and phenolic profile. Food Chem., 2005, 89, 27-36.

[31] Kulišić, T.; Dragović-Uzelac, V.; Miloš, M. Antioxidant activity of aqueous tea infusions prepared from oregano, thyme and wild thyme. Food Tech.Biotech., 2006, 44(4),485-492.

[32] Fecka, Z.; Turek, S. Determination of water soluble polyphenolic compounds in commercial herbal teas from lamiaceae: peppermint, melissa and sage. J. Agric. Food Chem., 2007, 55(26), 1090810917.

[33] Horbowicz, M.; Chrzanowski, G.; Koczkodaj, D.; Mitrus, J. The effect of methyl jasmonate vapors on content of phenolic compounds in seedlings of common buckwheat (Fagopyrum esculentum Moench). Acta Soc. Bot. Pol., 2011, 80(1), 5-9.

[34] Speisky, H.; Rocco, C.; Carresco, C.; Lissi, E.A., López-Alarcón, C. Antioxidant screening of medicinal herbal teas. Phytother. Res., 2006, 20(6), 462-467.

[35] Lee, K.W.; Kim, Y.J.; Lee, H.J.; Lee, C.Y. Cocoa has more phenolic phytochemicals and a higher antioxidant capacity than teas and red wine. J. Agric. Food Chem., 2003, 51, 7292-7295.

[36] Zaporozhets, O.A.; Krushynska, O.A.; Lipkovska, N.A.; Barvinchenko, V.N. A new test method for the evaluation of total antioxidant activity of herbal products. J. Agric. Food Chem., 2004, 52, 21-25.

[37] Pizarro, F.; Olvares, M.; Hertrampf, E.; Walter, T. Factors which modify the nutritional state of iron: tannin content of herbal teas. Arch Latinoam. Nutr., 1994, 44(4): 277-280.

[38] Tabasum, S.; Ahmad, S.; Akhlaq, N.; Rahman, K. Estimation of tannins in different food products. Int. J. Agric. Bio., 2001, 3(4), 529-530.

[39] Wikipedia. Tannin. Available from: http://en.wikipedia.org/wilhil /Tannin [accessed April 4, 2009]

[40] Chang, H-G.; Huang, G-J.; Agrawal, D.C.; Kuo, C-L.; Wu, C-R.; Tsay, H-S. Antioxidant activities and polyphenol contents of six folk medicinal ferns used as "Gusuibi". Bot. Stud., 2007, 48, 397406.

[41] Prior, R. L.; Wu, X.; Schaich, K. Standardized methods for the determination of antioxidant capacity and phenolics in foods and dietary supplements. J. Agric. Food Chem., 2005, 53(10), 42904302.

[42] Apak, R.; Güclü, K.; Demirata, B.; Özyürek, M.; Celik, S.E.; Bektasoğlu, B.; Berker, K.I.; Ozyurt, D. Comparative evaluation of various total antioxidant capacity assays applied to phenolic compounds with cuprac assay. Molecules, 2007, 12, 1496-1547.

[43] Yu, L.L. Methods for antioxidant capacity estimation of wheat and wheat- based food products. In: Wheat Antioxidants; WileyInterscience, New York, USA, 2007, Chapter 9.

[44] Zhang, D.; Hamauzu, Y. Phenolic compounds, ascorbic acid, carotenoids and anti-oxidant properties of green, red and yellow bell peppers. Food, Agric. \& Environ., 2003, 1(2), 22-27.

[45] Techaratonakrai, B.; Chaiwanichsiri, S.; Laohasongkram, K. Effects of infusion temperature and time on antioxidant activity of herbal infusions. In: Proceedings of the $33^{\text {rd }}$ Congress on Science and Technology of Thailand, October 18-20, 2007. 
[46] Pellegrini, N.; Serafini, M.; Colombi, B.; Del Rio, D.; Salvatore, S.; Bianchi, M.; Brighenti, F. Total antioxidant capacity of plant foods, beverages and oils consumed in Italy assessed by three different in vitro assays. J. Nutr., 2003, 133, 2812-2819.

[47] Hagerman, A.E.; Riedl, K.M.; Jones, G.A.; Sovik, K.A.; Ritchard, N.T.; Hartzfeld, P.W.; Riechel, T.L. High molecular weight plant polyphenolics (Tannins) as biological antioxidants. J. Agric. Food Chem., 1988, 46(5), 1887-1892.

[48] Anesini, C.; Ferraro, G.E.; Filip, R. Total polyphenol content and antioxidant capacity of commercially available tea (camellia sinensis) in Argentina. J. Agric. Food Chem., 2008, 56, 92259229.
[49] Duda-Chodak, A.; Tarko, T.; Sroka, P.; Satora, P. Antioxidant activity of different kinds of commercially available teas: diversity and changes during storage. EJPAU 11(4): \#07. Available from: http://www.ejpau.media.pl/volume11/issue4/art-07.html. [accessed May 22, 2009].

[50] Wang, C.C.; Chung, Y.C.; Chin, K.O.; Choy, K.W.; Khaw, K.S.; Rogers, M.S.; Pang, C.P. Trolox-equivalent antioxidant capacity assay versus oxygen radical absorbance capacity assay in plasma. Clin. Chem., 2004, 50(5), 952-954.

[51] Khan, S.A.; Khan, L.; Hussein, I.; Shat, H.; Akhtar, N. Comparative assessment of heavy metals in Euphorbia helioscopia L. Pak J. Weed Sci. Res., 2008, 14(1-2), 91-100.

Received: December 07, 2011

Revised: December 20, 2011

Accepted: December 28, 2011

(C) Bailey-Shaw et al.; Licensee Bentham Open.

This is an open access article licensed under the terms of the Creative Commons Attribution Non-Commercial License (http:/creativecommons.org/ licenses/ by-nc/3.0/) which permits unrestricted, non-commercial use, distribution and reproduction in any medium, provided the work is properly cited. 